PAPERS IN PHYSICAL OCEANOGRAPHY AND METEOROLOGY

Published By

MASSACHUSETTS INSTITUTE OF TECHNOLOGY

AND

WOODS HOLE OCEANOGRAPHIC INSTITUTION

(In continuation of Massachusetts Institute of Technology Meteorological Papers)

VOL. IV, NO. 2

\title{
DISGUSSION AND ILLUSTRATION OF PROBLEMS \\ SUGGESTED BY THE ANALYSIS OF \\ ATMOSPHERIC CROSS-SECTIONS
}

BY

H. C. WILLETT

CAMBRIDGE, MASSACHUSETTS

July, 1935 


\section{TABLE OF CONTENTS}

Pages

I. Introduction . . . . . . . . . . . . . . . . . . . . $3^{-6}$

A. Preliminary Remarks . . . . . . . . . . . . . . $3^{-4}$

B. Observational Material . . . . . . . . . . . . . . . 4

C. Use of Observational Data . . . . . . . . . . . . . . . 4-6

II. General Discussion of Questions Raised by the Analysis of AtmosPhertc Cross-sections . . . . . . . . . . . . . . . . . 7-33

A. Air Mass Identification Questions . . . . . . . . . . $\quad$ i-15

I. The Designation of the $\boldsymbol{T}_{\mathrm{S}}$ Air Mass . . . . . . . . 8-I I

2. The Vertical Structure of the $\mathbf{P}_{\mathrm{C}}$ Air Masses . . : . . . II-I5

B. Air Mass Interaction Questions . . . . . . . . . . . ${ }^{15-33}$

I. The Location of the Front Surface in a Transition Zone . . I5-16

2. Frontal Structure and Interaction between the Tropical Superior and the Tropical Maritime Air Masses . . . . : . . 17-24

3. Air Mass Interactions Occurring above Extensive Surface Cold Polar Air Masses . . . . . . . . . . . . . $24-27$

4. The Polar-Tropical Air Mass Contrasts, and the Variation with Elevation of the Sharpness of the Fronts between Them . . 27-30

5. The Structure of the Fronts between $\mathbf{P}_{P}$ and $\mathbf{P}_{C}$ Air Masses, and of the Secondary Fronts within $\mathbf{P}_{\mathrm{C}}$ Air Masses . . . . 30-33

III. Notes on Features of Interest on the Individual Cross-sections . 34-4i

A. First Period (Dec. 6-8, I93I) . . . . . . . . . . . . . . . 34-35

B. Second Period (Jan. 12-16, 1932) . . . . . . . . . . . . . . . $35-38$

C. Third Period (Feb. 8-10, 1933) . . . . . . . . . . . . . . . 38-39

D. Fourth Period (Oct. I4-I7, I933) . . . . . . . . . . . . 39-4I 


\section{INTRODUCTION}

\section{A. Preliminary Remarks}

The preparation of atmospheric cross-sections, in which the fields of the various meteorological elements are represented in the vertical plane containing a number of synoptic aerological soundings, has long been a part of the technique applied to the investigation of problems in synoptic meteorology. ${ }^{1}$ However, owing to the lack of adequate observational material, the number of such cross-sections prepared in the past has been very small. The method was applied only in a few cases chosen for careful analysis and study. Consequently no uniform technique of analysis of such cross-sections has been developed, nor have the possibilities of this method of synoptic investigation received much attention.

In the fall of I 933 the author decided that the possibilities of the cross-section method of synoptic representation warranted the systematic preparation and analysis of a large number of cross-sections. For this purpose a number of periods during which the synoptic maps seemed to indicate interesting atmospheric developments, and for which numerous aerological observations were available, were chosen from the maps of the preceding two or three years for detailed cross-sectional study. In all, ten periods of from two to six days each were chosen, a total of 36 days, entailing the preparation of about 90 cross-sections, and the use of about 400 aerological soundings.

The results proved to be so interesting and instructive that it was decided by Prof. Rossby and the author to try to simplify the preparation of cross-sections to a point where it might be made a part of the daily weather map routine. This was effected by the use of graphical methods of evaluation of the aerological soundings, and by the printing of standard cross-section forms. ${ }^{2}$ The regular preparation of similar standard crosssections has been undertaken since by meteorologists of the United States Weather Bureau, notably by $\mathrm{H}$. Wexler.

The present paper is concerned only with the presentation of the results of the earlier selected short periods chosen for cross-sectional study. A general formulation of the problems of interest suggested by this initial cross-sectional analysis is attempted, and specific instances are cited and cross-sections reproduced in illustration of the more important of these questions. In most cases, however, no final conclusions are offered concerning the solution of the problems raised or their full significance for practical weather forecasting. Such definite conclusions cannot be formulated until after more experience with the preparation of the standard daily cross-sections and their application in practical forecast work. Nevertheless, a preliminary discussion such as the present

${ }^{1}$ E. X. by J. Bjerknes, Palmén, Namias, and others.

${ }^{2}$ H. C. Willett, Routine Daily Preparation of Atmospheric Cross-Sections, Monthly Weather Review, January, 1935 
one should be of value in calling attention to certain features of the synoptic maps which are likely to be overlooked when one works only with the surface analysis and the aerological soundings individually rather than collectively.

\section{B. Observational Material}

For the synoptic study of the selected periods the following observational data were available:

(I) The regular surface reports from the United States and Canada as broadcast twice daily over NAA.

(2) The pilot balloon observations of winds aloft from Weather Bureau stations in the United States as broadcast twice daily over NAA.

(3) All aerological soundings made at Weather Bureau or Navy Stations, and at the M.I.T. station at East Boston airport. An effort was made to include a number of days in the periods selected during which series of two or more soundings at short intervals were made at Boston. The Weather Bureau stations at which daily soundings were made during some or all of the periods chosen were the kite stations at Ellendale, N.D. and Due West, S.C., and the aeroplane stations at Pembina, N.D., Omaha, Neb., Dallas, Tex., Chicago, Ill., Cleveland, O., and Atlanta, Ga. The Navy aeroplane stations were located at San Diego, Cal., Pensacola, Fla., Norfolk, Va., and Anacostia, D.C. It should be mentioned that although the number of active aeroplane stations during these periods was smaller than the present number, the greater regularity of the weather bureau stations at Dallas, Omaha, Chicago, and Cleveland in completing their flights under adverse weather conditions was of great assistance in this work. It was possible to complete cross-sections in cases of interest when conditions were such that flights would not have been attempted under the present organization of the Weather Bureau, Army, or Navy meteorological flight work. Credit should be given to the commercial pilots making the Weather Bureau ascents at Dallas, Omaha, Chicago, and Cleveland during the years I93I, I932, and I933 for the excellent records which they made.

(4) For a few periods given especially close study there were obtained the hourly observations from Mt. Washington Observatory, through the cooperation of the chief observer, Mr. Pagliuca, and detailed cloud observations from Blue Hill Observatory, through Dr. C. F. Brooks.

\section{Use of Observational Data}

Besides the usual 8A.M. and 8P.M. surface synoptic charts, and the corresponding upper level wind charts showing the pilot balloon observations, atmospheric cross-sections were prepared for each day of the periods chosen for this study. Furthermore, as an aid to the analysis both of the surface maps and of the cross-sections, Rossby diagrams were plotted for every aerological sounding available for the selected periods. For several of these periods, to avoid duplication of work, the author took advantage of the evaluation and plotting of soundings which had been made by J. Namias in his investigation of subsidence in the atmosphere.

In the preparation of the atmospheric cross-sections the elements temperature, potential temperature, and specific humidity were plotted at each significant level of each sounding. Wind velocities were entered at the standard levels when pilot balloon observations had been made at nearly the same time as the aerological sounding. Cloud forms and elevations, and haze layers, were entered when observations were available. 
The analysis of the cross section was made in conjunction with that of the surface map, in most cases.

Three cross-sections were prepared for each day for which data were available. These sections included the following stations:

(I) Boston, Mass., Cleveland, O., Chicago, Ill. (inactive during a few of the periods) and Omaha, Neb. These station names are abbreviated on the cross-sections to $\mathrm{B}, \mathrm{Cl}, \mathrm{Ch}$ and $\mathrm{O}$ respectively. This east-west section is always referred to as section $\mathrm{A}$ for any given date.

(2) Dallas, Tex., Omaha, Neb., and either Ellendale, N.D., or Pembina, N.D., depending upon which station was active during the given period. These station names are abbreviated to $\mathrm{D}, \mathrm{O}, \mathrm{E}$, and Pem, respectively, on the cross-section. This north-south section is referred to as section $B$ for any given date.

(3) Boston, Mass., Anacostia, D.C., Norfolk, Va., Due West, S.C. (inactive during some periods), Atlanta, Ga., (inactive during most periods), Pensacola, Fla., and Dallas, Tex. These station names are abbreviated to $\mathrm{B}, \mathrm{A}, \mathrm{N}, \mathrm{DW}, \mathrm{At}, \mathrm{P}$, and $\mathrm{D}$ respectively. This southern section is referred to as section $C$ for any date. The location of the sections $\mathrm{A}, \mathrm{B}$, and $\mathrm{C}$ is indicated at the beginning of the cross-section illustrations (Plate I).

For purposes of illustration in the present paper four short periods, totalling fifteen days, were selected from the total of ten periods studied. They were chosen in each case because they illustrated particularly well some one or more of the problems or questions arising during the analysis of the cross-sections. The periods selected for this purpose were Dec. 6-8, I931, Jan. I2-16, I932, Feb. 8-IO, I933, and Oct. I4-I7, I933. For these periods the 8 A.M. surface map covering the area of the United States and the analyzed cross-sections based on the morning soundings of the same date, are reproduced at the end of this paper. Each of the three cross-sections listed above as nos I, 2, and 3, and referred to in the text as $\mathrm{A}, \mathrm{B}$, and $\mathrm{C}$ are reproduced for each of these days on which the data are sufficient.

The surface maps are analyzed and reproduced in the usual way, with this one departure from the earlier procedure in the M.I.T. publications, namely, - warm fronts are represented as heavy dotted lines instead of double light lines, which are likely to be confused with isobars. On the cross-sections it is necessary occasionally to represent a surface of subsidence, which of course never appears on the surface maps. This type of almost horizontal discontinuity is represented as a broken and dotted heavy line. Occluded fronts do not appear on the cross-sections, as the warm and cold front designations are retained at upper levels even after surface occlusion. The four frontal designations then, appearing on surface maps or cross-sections, are as follows:-

I. Cold front

2. Occluded front

3. Warm front

4. Subsidence surface

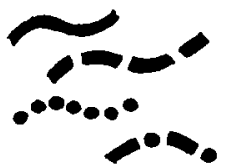

continuous heavy line

broken heavy line dotted heavy line

The cross-sections are all reproduced in duplicate, to avoid the crowding of too much data and too many isopleths on one section. On one section are plotted the temperature and the wind directions, where the latter are available. The directions indicated by the wind arrows are chosen so that the west-east direction is always parallel to the base line of the section, from left to right. Isotherms are drawn for each $5^{\circ} \mathrm{C}$ as continuous light lines. On the second section are plotted the potential temperature on the absolute scale, 
the specific humidity in $\mathrm{g} / \mathrm{kg}$, and all observations of clouds, haze layers, etc. Whenever they are known the top and bottom of the cloud and haze layers are indicated. On this section the potential temperature isotherms for each $5^{\circ} \mathrm{C}$ are drawn as continuous light lines, and the isopleths of specific humidity as broken light lines.

It will be noted that in the analysis of the cross-sections changes in slope of the isopleths are made discontinuous at the front surfaces when the data permitted. Also that the frontal surfaces, which are in reality not surfaces but transition zones, were systematically placed on the side of the transition toward the warmer air mass. The result is that most of the transition between air masses, and consequently most of the slope of the isopleths, occurs within the colder, or Polar, air masses. This convention has generally been followed by the Norwegian meteorologists. But quite apart from the transition zones between the air masses, within the Polar and Tropical air masses proper, the isopleths are usually much more nearly horizontal in the latter than in the former. This indicates the difference in horizontal homogeneity which has long been held as characteristic of the two fundamental air mass types. 


\section{GENERAL DISCUSSION OF QUESTIONS RAISED BY THE ANALYSIS OF ATMOSPHERIC CROSS-SECTIONS}

In the course of applying the methods of air mass analysis to the development of a technique suitable to the analysis of atmospheric cross-sections, attention was inevitably focused on a number of rather puzzling conditions frequently indicated by aerological soundings in the United States, but conditions which receive only scant attention in the course of the analysis of the surface weather maps. The real problem in most of these doubtful conditions is a question either of air mass identification or of the interpretation of the interaction of two air masses at a front. The questions to be considered here, then, may be classified as dealing either with the identification and proper designation of the air masses appearing at upper levels, or with the correct interpretation and representation of the interaction aloft between these different air masses. The identification of air masses at high levels on the cross-section is frequently much more difficult than it is on the surface map. There are several reasons for this, in particular:

(I) The lack of observations from the upper levels by which to determine the recent trajectory of the air reaching the point of observation.

(2) The extreme unreliability of the hair hygrometer readings of humidity at low temperatures and pressures.

(3) The surprising degree of stratification frequently observed aloft, which permits the rapid relative movement of rather thin air mass strata that may differ widely in source and properties.

After the different air masses aloft are correctly identified and designated on the crosssection, there are questions continually coming up as to the proper location of the front surface in the transition zone between two air masses, or as to the frontal structure and the interaction between two air masses whose temperature difference vanishes or reverses itself with elevation. In cases of steep warm and cold front surfaces, when the horizontal extent of the front is rather small, it is exceptional to find two soundings penetrating the frontal surface. Consequently it has not been possible, with the network of stations used in this study, to determine much about the slope and structure of the steeper fronts which are just the ones which are of real interest, dynamically. Even with the present network of aerological stations in operation, such a study will be difficult unless a higher operating efficiency in bad weather is maintained. In a few instances, however, interesting information on frontal structure was obtained by series ascents of the M.I.T. plane at East Boston.

There are two particular questions having to do with air mass identification, both rather broad in scope, which come up repeatedly in connection with the cross-section work. They require rather careful consideration in this discussion:

(I) The identification, the source region, and the synoptic significance of the warm dry air prevailing so much of the time at intermediate and high levels over the southern and central United States. 
(2) The explanation of the usual stratification observed in the upper levels of the cold $\mathbf{P}_{\mathrm{C}}$ air masses. We are especially concerned with the correct air mass designation, the source, and the synoptic significance of the relatively warm moist strata so frequently observed overlying the cold $\mathbf{P}_{\mathrm{C}}$ air at the ground.

In connection with the location, structure, and dynamic significance of the transition zones or front surfaces between adjacent air masses, the following questions have been chosen for consideration in the present discussion of atmospheric cross-sections:

(I) The proper location of the front surface within the frequently rather broad transition zone between two air masses.

(2) The frontal structure and interaction of the warm moist $\mathbf{T}_{M}$ air masses $\left(\mathbf{T}_{G}, \mathbf{T}_{A}\right.$, and $\mathbf{T}_{\mathrm{P}}$ ) with the warm dry $\mathbf{T}_{\mathrm{S}}$ air mass, at upper levels.

(3) The nature of the air mass movements and interactions which frequently occur above relatively shallow inactive strata of cold $\mathbf{P}_{\mathrm{C}}$ air at the ground.

(4) The variation with elevation of the sharpness of the frontal discontinuities between the Polar and the Tropical air masses.

(5) The vertical structure of the fronts between the Polar air masses, and of the occluded and secondary cold fronts within $\mathbf{P}_{\mathrm{C}}$ air.

Evidently the two questions dealing with the identification of air masses aloft must be considered before those having to do with the dynamic interaction of different air masses. Therefore the discussions of the two air mass questions and of the five frontal interaction questions listed above follow in the same order in Sections A and B respectively.

\section{A. Air Mass Identification Questions}

\section{The Designation of the $\mathbf{T}_{\mathrm{s}}$ Air Mass}

The frequent appearance of warm dry air strata above the moist $\mathbf{T}_{M}$ air masses has been recognized since the first study of the properties of the American air masses. Occasionally such a dry stratum of air is found to be sandwiched between two moist strata. Usually the base of the dry stratum is marked by a temperature inversion, or at least by a markedly stable or isothermal layer. The base of the dry air may be found at any level above $600 \mathrm{~m}$, though there is a tendency for it to be found higher as one goes northward or eastward from Texas and Oklahoma. An ideal case of the occurrence of warm dry $\mathbf{T}_{\mathrm{S}}$ strata above $\mathbf{T}_{\mathrm{G}}$ and other surface air masses will be found on the cross-sections for Jan. I4, I5, and I6, I932 (Plate X ff.).

It was the author's former conviction ${ }^{1}$ that these dry warm strata of air should be treated as an integral part of the Tropical maritime air masses. This implied that the dry air was moving with the moist air beneath, from the same source region, that it was more or less coextensive with the maritime mass, and that the dryness was the result of the air mass stability and consequent checking of the vertical transport of moisture by convective or mechanical turbulence. However, the study of atmospheric cross-sections has shown this point of view to be untenable. Actually the warm dry air aloft is found to be much more widespread in its occurrence than are the $T_{M}$ air masses. It occurs not only generally above the moist $\mathbf{T}_{M}$ air masses, but also above the transitional and even fresh Polar air masses. Its distribution, both latitudinal and longitudinal, is more extended than that of the $\mathbf{T}_{M}$ air masses, at least in winter, while its movement is

${ }^{1}$ H. C. Willett, American Air Mass Properties. 
usually directed much more from west to east, and less from south to north, than is that of the $\mathbf{T}_{\mathrm{M}}$ air. These facts were brought out much more clearly in the present analysis of atmospheric cross sections than in the author's earlier studies of the air mass properties, for in the earlier air mass studies the aerological soundings were studied individually, on the basis of the surface analysis only, and attention was concentrated on the more nearly ideal instances of the occurrence of each air mass type. This tended naturally to eliminate cases of pronounced air mass stratification at low levels. Also the earlier soundings were mostly by kites which failed to reach as high elevations on the average as the aeroplanes do, and which were especially ineffective in gaining altitude in cases of marked atmospheric stratification.

The existence of marked differences between the moist $\mathbf{T}_{M}$ air masses and these upper warm dry strata in their distribution, movement, and presumably also in their source, requires that they be given different air mass designations and be treated as distinct air masses whenever they occur. The symbol $\mathrm{T}_{\mathrm{S}}$ was chosen to designate the warm dry air masses usually found at upper levels, and they are referred to as Tropical superior. Mean values of the characteristic properties of the $\mathbf{T}_{\mathrm{S}}$ air mass have not been determined, but midsummer and midwinter values of temperature and moisture characteristic of this air mass at the $2 \mathrm{~km}$ level above San Antonio, Tex., and Omaha, Neb., both stations at which its occurrence is quite frequent, are about as follows:

\begin{tabular}{|c|c|c|c|c|c|}
\hline & \multicolumn{2}{|c|}{ January } & \multicolumn{3}{|c|}{ July } \\
\hline & $\mathrm{T}^{\circ} \mathrm{C}$ & $\mathrm{q} \quad \mathrm{g} / \mathrm{kg}$ & $\mathrm{T}^{\circ} \mathrm{C}$ & $\mathrm{q}$ & $\mathrm{g} / \mathrm{kg}$ \\
\hline San Antonio & 10 & 3 & 24 & & 5 \\
\hline Omaha & 5 & 2 & 22 & & 5 \\
\hline
\end{tabular}

The $\mathbf{T}_{\mathrm{S}}$ air mass is the warmest mass observed in the United States at low and intermediate levels, where it averages several degrees warmer than $\mathbf{T}_{G}$ air. But owing to the steep lapse rate characteristic of the $\mathbf{T}_{\mathrm{s}}$ air mass at higher levels, this temperature difference is likely to change its sign near the $4 \mathrm{~km}$ level, and the negative difference to increase above this level. The lapse rate found aloft in the $T_{S}$ air mass, often close to the dry adiabatic rate, could not persist in a moist air mass of the same temperature. The relative humidity in the lower levels of the $\mathrm{T}_{\mathrm{S}}$ air mass is characteristically less than $40 \%$, of ten falling below $20 \%$, or even $10 \%$ at higher levels. The specific humidities indicated above as characteristic of the $2 \mathrm{~km}$ level usually decrease rapidly with elevation, so that even in summer a value of $\mathrm{q}$ of less than I $\mathrm{g}$ may be observed in this air mass at San Antonio above the $4 \mathrm{~km}$ level. The principal identifying distinction between the $\boldsymbol{T}_{\mathrm{S}}$ air mass and the $\mathbf{T}_{M}$ air masses is the moisture difference. The distinction between the $\mathbf{T}_{\mathrm{S}}$ mass and the subsiding dry strata of air masses of Polar origin is the temperature difference. The $\mathbf{T}_{\mathrm{S}}$ air is usually considerably warmer than air of Polar origin, even after a large amount of subsidence of the latter. There is no distinction between $\mathbf{T}_{\mathrm{S}}$ air and the air masses formerly designated as $\mathbf{T}_{\mathrm{C}}$. They are the same thing. The $\mathbf{T}_{\mathrm{C}}$ designation implied an extensive surface source region of the Tropical continental air masses in North America. The $\mathbf{T}_{\mathrm{S}}$ designation recognizes the fact that there is no such extensive surface source region on this continent, that the $\mathbf{T}_{\mathrm{S}}$ air masses which appear principally at upper levels and are very widespread in their distribution cannot, therefore, have a surface source 
region. The occurrences of air at the surface, formerly designated as $\mathbf{T}_{C}$, are only special cases in which widespread $\mathbf{T}_{\mathrm{S}}$ currents aloft work their way down to the surface.

Such appearances of $T_{S}$ air at the ground occur most frequently in the region from Texas northward over the western Plains states, especially in summer, though they may occur at any season. They are always characterized by warm dry weather, and in summer by severe dry heat. Further north from the southwestern Plains region the tendency is always towards the occurrence of wedges of Polar air of increasing depth at the ground. This is especially true of the colder season. Further eastward from this region, over the southern and central United States, we usually find to increasing elevations above the ground the presence of other air masses.

In summer these are the moist and somewhat cooler $\mathbf{T}_{\mathrm{G}}$ masses from the Gulf of $\dot{\mathrm{M} e x-}$ ico, and in winter the deepening flows of $\mathbf{P}_{\mathrm{C}}$ air from the north which are characteristic of the eastern side of continental areas during the cold season.

Apart from the fact that the normal movements of both the Polar air masses and the Tropical maritime masses are such that their vertical extent in the southwestern Plains states is likely to be slight, there are two other factors which tend to favor the appearance of the $\mathbf{T}_{\mathrm{s}}$ currents at or near the ground in this region, namely:

(I) The Föhn action of the western mountain ranges. Since the $T_{S}$ currents usually have rather high velocities from a westerly direction, the drag effect of the mountains helps this warm current to scour out shallow colder air masses over the western Plains area.

(2) The large diurnal temperature range characteristic of the semi-arid southwestern Plains area throughout the year, and especially in summer. The daytime heating of the shallow colder air mass helps to destroy the thermal stratification and consequently to assist the scouring action of the warm current aloft in removing the surface air mass stratum.

The origin of the $\mathbf{T}_{\mathrm{S}}$ air mass is somewhat uncertain. Its warmth indicates almost without question that it is of tropical origin. Its extreme dryness requires that it shall have had a rather extended past history during which it has remained aloft, and even indicates that it has been undergoing a descending movement for some time. Consequently the logical source region to attribute to the $\mathbf{T}_{\mathrm{s}}$ air mass is the upper portion of the subtropical belt of high pressure. This air mass, consequently, is unique among the American air masses in that the acquisition of its source properties takes place at upper levels in the atmosphere and quite independently of any direct contact influence of the ground surface in this region.

We know that slow sinking of poleward moving air must be occurring in the subtropical belt of high pressure. This sinking is especially concentrated in the great anticyclonic cells in this high pressure belt, and, according to the scheme of J. Bjerknes, ${ }^{1}$ especially on the northern sides of these anticyclonic cellular units. Thus we should expect the prevailing westerly winds aloft in south temperate latitudes to be composed mostly of $\mathbf{T}_{\mathrm{S}}$ air, and to find the $\mathbf{T}_{\mathrm{S}}$ at especially low levels in the northeastern quadrants of the subtropical anticyclones. It should be found at higher levels as we pass northward into regions where the Polar air masses predominate to high elevations. The observations of the distribution of the $T_{\mathrm{S}}$ air currents in the United States verify these assumptions. It is not always possible, however, with our limited aerological observations, to ascertain definitely in which anticyclonic cell, Atlantic or Pacific, the $\mathbf{T}_{\mathrm{S}}$ air mass takes its source

${ }^{1}$ Physikalische Hydrodynamik, mit Anwendung auf die dynamische Meteorologie, J. Springer, Berlin, I933. 
in a given instance. For this reason no attempt is made to express in the air mass symbol the particular source cell in each case, for it should make little difference in the air mass properties. It is noticeable, however, that this air mass occurs very frequently at low levels in the southern California region, which lies in the northeastern quadrant of the Pacific anticyclone at the surface. Furthermore, in winter strong west or west-northwest winds aloft seem to bring the $\mathbf{T}_{\mathrm{s}}$ air from this region directly across the southern United States quite frequently. In summer the upper wind distribution in the southwestern United States, as shown by T. R. Reed, ${ }^{1}$ is quite different. The Atlantic anticyclone, in accordance with Bjerknes's scheme, is displaced far to the westward as low as at the $4 \mathrm{~km}$ level. Moist southeast and south winds $\left(\mathbf{T}_{\mathrm{G}}\right.$ air) frequently predominate at upper levels over the southern Rocky Mountain and Plateau Regions. At such times the driest $\mathbf{T}_{\mathrm{S}}$ air is found over the Plains states, and apparently belongs to the descending current in the northeast quadrant of the Atlantic cell at a few kilometers above the ground.

It is pointless to speculate in further detail about the sources and movements of these upper level air masses without a more thorough analy tical study of the aerological observations. Such a study should have considerable synoptic significance, not only in clarifying our ideas about the cellular structure of the general circulation, but also in explaining many interesting features in the day to day developments on the synoptic charts. We shall have occasion a little later, in the discussion of the $T_{G}$ and $T_{S}$ air mass interactions to touch on the significant role played by the $\mathbf{T}_{\mathrm{S}}$ air mass in some of our weather sequences.

\section{The Vertical Structure of the $\mathbf{P}_{\mathrm{C}}$ Air Masses}

The $\mathbf{P}_{\mathrm{C}}$ air mass, during most of the year, is the coldest and driest of the North American air masses, at least at low levels. It is, however, usually found to be very stratified in its vertical structure, showing frequently marked inversions both in temperature and moisture. ${ }^{2}$ Occasionally this air mass is found to be uniformly cold and dry throughout its vertical extent, or at least as far up as the observations extend, which is usually to 5 or $6 \mathrm{~km}$. These cases of comparative vertical homogeneity of the $\mathbf{P}_{\mathrm{C}}$ air mass are definitely exceptional. Even then the mass must be definitely stable throughout most of its vertical extent, for a surface temperature between $-20^{\circ}$ and $-30^{\circ} \mathrm{C}$, in a latitude of about 45 degrees, excludes the possibility of more than a slight lapse rate extending up to the $6 \mathrm{~km}$ level. But in these exceptional cases any temperature inversions which occur are very small, and specific humidity inversions are lacking. The deep uniformly cold $\mathbf{P}_{\mathrm{C}}$ outbreaks occur principally over the eastern half of the continent, and in cases when steep pressure gradients and strong northerly winds occur throughout the vertical extent of the air mass. Under these conditions the surface temperatures average higher than in the slowly moving shallow $\mathbf{P}_{\mathbf{C}}$ cold strata. It is the relatively frequent occurrence of strong outflows of $\mathbf{P}_{\mathrm{C}}$ air of this type, with very low temperatures aloft, which accounts for the fact that $\mathbf{P}_{\mathrm{C}}$ air at Boston at the $4 \mathrm{~km}$ level averages $4^{\circ} \mathrm{C}$ colder than at Ellendale N.D. at the same level. (Cf. American Air Mass Properties.) An excellent instance of a deep uniformly cold $\mathbf{P}_{\mathbf{C}}$ air mass of this type will be found on the cross-sections of $F e b$. 8-IO, I933 (Plate XVI ff.). It is interesting to note in passing that the condition of strong winds aloft which is always found accompanying a deep relatively homogeneous $\mathbf{P}_{\mathrm{C}}$ current is also found always to accompany the exceptional case of a deep relatively homogeneous $\mathbf{T}_{\mathrm{G}}$ current.

1 The North American High Level Anticyclone, Monthly Weather Review, Nov. I933.
${ }^{2}$ H. C. Willett, American Air Mass Properties. 
Normally, however, even in the source region, the $\mathbf{P}_{\mathrm{C}}$ air mass is found to be markedly stratified. The stratification is found to be most pronounced in the more western portion of the source region, along the eastern slope of the Rockies. This is shown very clearly in meteorological ascents at Fairbanks, Alaska, and it has been indicated also at Edmonton and Calgary, Alberta. In this region the warmth and moisture found at upper levels in the $\mathbf{P}_{\mathrm{C}}$ air mass unquestionably belong to air strata which have moved in from the Pacific, by passing eastward over the Rockies and the Coastal ranges, and which are only slowly cooled and dried at their high elevation above the cold continental surface. Further eastward we find that the cooling and drying of these upper strata has been continuing slowly. At Ellendale, N.D., we still find normally a large temperature inversion and moderate increase in specific humidity between the ground and the $2 \frac{1}{2}$ or $3 \mathrm{~km}$ levels. Even at Chesterfield Inlet, on the northwestern shore of Hudson Bay, the Polar Year soundings showed a thermal stratification very similar to that at Ellendale, although temperatures seemed to average some $6^{\circ} \mathrm{C}$ colder throughout. A vertical air mass structure almost identical with that at Chesterfield Inlet was found by Sverdrup on the Maud Expedition in the frozen Arctic during the Polar night. We may then conclude that a marked thermal stratification and a moderate moisture stratification is typical of all air masses of the $\mathbf{P}_{\mathrm{C}}$ type, during the cold season, in any continental or effectively continental (frozen maritime) source region. This would be expected from the fact that the acquisition of the properties of air masses in such source regions is effected principally by the influence of the frozen ice and snow surface beneath, which is radiationally cooled to very low temperatures. Furthermore the thermal stratification, and even more markedly the moisture stratification, will be greatly increased by the presence of adjacent open maritime regions. There will always be a tendency for the comparatively warm moist maritime air to move in above the coldest surface regions. This tendency will be particularly pronounced in north temperate latitudes, on the west side of continents, where mountain barriers protect the cold air at low levels against the normal eastward advance of the maritime masses. This explains the partial disappearance of the moisture stratification and the slight weakening of the temperature stratification as one passes eastward from the Rockies to Hudson Bay in our own $\mathbf{P}_{\mathrm{C}}$ air mass source region.

There are two questions which arise naturally from the above discussion, and which should at least be mentioned in passing:

(1) Should the designation $\mathbf{P}_{\mathrm{C}}$ be applied to this entire non-homogeneous body of air found in the $\mathbf{P}_{\mathbf{C}}$ source regions, or should this designation be reserved for the more or less uniformly cold and dry strata usually found only in the lower $2 \mathrm{~km}$ of the atmosphere in such a region?

(2) How are the occasional deep uniformly cold and dry $\mathbf{P}_{C}$ currents to be accounted for?

The proper application of the $\mathbf{P}_{\mathrm{C}}$ designation to the extremely stratified air masses observed in the $\mathbf{P}_{C}$ source region is a question only of definition or convention. On the cross-sectional analyses discussed in this paper, and in general in the synoptic analysis work at M.I.T., the $\mathbf{P}_{C}$ designation is used for all air masses originating in the $\mathbf{P}_{C}$ source region. The degree of stratification makes no difference as long as the upper as well as the lower strata of the air mass appear to have advanced in one integral movement from the same source region. The stratification or non-homogeneity is accepted as characteristic of the $\mathbf{P}_{\mathrm{C}}$ air. On the other hand, when the upper warm or moist strata belong to another air movement, i.e., belong to another air mass advancing from a different source region, then the effort is made to retain the distinctive air mass designation aloft. This 
distinction is not always easy to make with certainty, but it is usually indicated by more rapid changes aloft than at the ground in the coldest $\mathbf{P}_{\mathrm{C}}$ air. A good illustration of the rapid advance of other air masses above cold $\mathbf{P}_{\mathrm{C}}$ will be found on the cross-sections from Feb. 8-10, I933 (Plate XVI ff.).

The occurrence of occasional deep currents of fairly homogeneous and very cold $\mathbf{P}_{\mathrm{C}}$ air can be explained only in a very general qualitative way. In the first place, they have their source principally in the central and eastern portions of the $\mathbf{P}_{\mathrm{C}}$ source region, where the atmosphere is more homogeneous and colder to begin with than in the northwest. And in the second place they occur only following intense occluded disturbances, i.e., with strong northerly winds occurring up to high levels. This condition has the double effect of rapid transport of real Arctic air southward, and of rapid mixing of the current by mechanical turbulence.

We have seen that even in the source region the vertical structure of the $\mathbf{P}_{\mathrm{C}}$ air mass is complicated, so that it is necessary to take special cognizance of its normal stratification. But as this air mass moves southward and eastward from the source region the complication of its structure usually increases rather than decreases. Rapid changes in the air mass properties are likely to occur at all levels, so that the particular problem of placing the upper boundary of the true $\mathbf{P}_{\mathrm{C}}$ air mass becomes increasingly difficult. These changes are most pronounced when the air mass movement is slow, in which case most of the horizontal as well as the vertical homogeneity of the air mass disappears.

In order to explain the rapid modification of the $\mathbf{P}_{\mathrm{C}}$ air mass properties after its outflow from the source region, we must consider the lower coldest portion of the air mass (below the first principal temperature inversion) and the upper portion separately. The lowest stratum is modified principally by the influence of the surface over which the air mass is passing. The effects are principally those of the addition of heat and moisture, and the maintenance of a fair degree of homogeneity through the stirring produced by surface friction. As long as the air mass continues over a snow or ice surface, the surface layer changes slowly. Immediately on its passage over a warm ground surface, or much more over a warm water surface, the surface homogeneous layer becomes rapidly deeper, and is heated and moistened. Increased surface winds and a rough ground surface also tend to deepen the homogeneous layer. Such modification of the surface stratum of the $\mathbf{P}_{\mathrm{C}}$ air mass by the ground surface itself offers no complication in the analysis. It is expected, and can be directly measured in the surface observations. However, there is an upper level influence expressed in these surface changes which should not be overlooked. The pronounced stratification of the $\mathbf{P}_{\mathbf{C}}$ air mass in the first place probably accounts for the great rapidity with which these surface modifications may occur as the air mass moves southward. Usually the principal temperature inversion becomes lower as the $\mathbf{P}_{\mathrm{C}}$ air mass progresses southward, and correspondingly the rate of change of the surface air mass properties increases. This accounts for the fact that $\mathbf{P}_{C}$ air masses never bring temperatures to the Gulf Coast which are in any way comparable with those observed in the same air mass near the Canadian border, even when the southward advance of the air mass is very rapid. In cases of very slow movement, or stagnation, of the $\mathbf{P}_{\mathbf{C}}$ mass, it rapidly loses all horizontal homogeneity at the ground. This tendency is favored in such cases, usually, by the saturation of the surface layer of the air mass by precipitation falling from some moist overrunning air mass. We observe then a gradual transition from $\mathbf{T}_{\mathrm{G}}$ properties at the southern boundary of the $\mathbf{P}_{\mathrm{C}}$ mass to typical $\mathbf{P}_{\mathrm{C}}$ properties in the northern portion of the mass. 
But the real difficulty met with in the analysis of cross-sections through $\mathbf{P}_{\mathrm{C}}$ wedges lies in the interpretation of the changes which are usually observed to occur above the first principal temperature inversion in the southward moving air mass. The chief difficulty lies in making the distinction between subsidence and advection influences. It is natural to expect that the cold $\mathbf{P}_{\mathrm{C}}$ air mass moving southward should undergo rapid sinking and spreading as a result of its relatively high density.

It might be added here that the downward movement of the cold air supposed to be characteristic of the upper forward portion of the rapidly advancing cold wedge, and supposedly the cause of secondary cold front formation, does not make itself very evident in our American $\mathbf{P}_{\mathrm{C}}$ air masses. Frequently above the cold wedge a warm dry current is found, but its properties cannot possibly be explained as those of $\mathbf{P}_{\mathrm{C}}$ air modified by subsidence, the temperature is far too high at high elevations. (See the discussion of $\mathbf{T}_{\mathrm{G}}$ and $T_{\mathrm{S}}$ interaction above cold fronts, beginning p. I 7.) And within the stratified cold wedge the high moisture content of the upper strata in the forward portion of the cold wedge usually precludes a subsidence explanation of the warmth observed.

The effect of subsidence within the $\mathbf{P}_{\mathrm{C}}$ air mass is to bring the upper strata of the air mass closer to the ground, to heat them dynamically, and consequently to intensify and to bring lower the temperature inversions in the air mass. A thorough investigation of the subsidence process in American $\mathbf{P}_{\mathrm{C}}$ air masses has been made by $\mathrm{J}$. Namias, ${ }^{1}$ so that the subject will not be taken up in detail here. That subsidence is quite general in the cold $\mathbf{P}_{\mathrm{C}}$ currents coming southward is evidenced by the observational fact that the princi$\mathrm{pal}$ and secondary temperature inversions in $\mathbf{P}_{\mathrm{C}}$ air masses are found to increase and to be located at lower levels at the more southerly stations. This modification occurs so rapidly that the warming of the upper levels of the air mass is usually even greater than that of the surface stratum which is heated by the ground surface. The modification of the upper levels of the initially homogeneous and very cold $\mathbf{P}_{\mathrm{C}}$ currents takes place especially rapidly once the steep pressure gradient disappears. Consequently very rapid stabilization of the deep cold $\mathbf{P}_{\mathrm{C}}$ outbreaks usually occurs as they reach southerly latitudes, and this is usually accompanied by active anticyclogenesis in the subsiding air mass. It is obvious that the vertical extent of the original $\mathbf{P}_{\mathbf{C}}$ air mass must be decreasing very rapidly coincidentally with the southward progress of the air mass, and consequently, that in the south air masses of different origin must be looked for at relatively low levels above the $\mathbf{P}_{\mathrm{C}}$ wedge. The difficulty is to locate correctly the upper boundary of the $\mathbf{P}_{\mathrm{C}}$ mass. As long as the changes we observe aloft at a fixed level are the result only of subsidence within the original $\mathbf{P}_{\mathbf{C}}$ air mass, then the specific humidity at this level in the air mass must be decreasing, or at least constant. But the fact is that we usually observe a moderate increase in specific humidity even above the principal temperature inversion as the $\mathbf{P}_{\mathrm{C}}$ air mass advances southward. If the increase is only small, this can be explained by the sluggishness of the hair hygrometer ${ }^{2}$ at low temperatures. The increase then follows from the fact that as the air mass advances southward and becomes warmer at all levels, the actual increase of moisture in the surface homogeneous stratum results in the maintenance of a fairly high relative humidity at the ground. The sluggishness of the hair hygrometer as the meteorograph is carried into the dry upper strata prevents the instrument from indicating a decrease in relative humidity as great as that which the

1 Subsidence within the Atmosphere, Harvard University Press, 1934.

${ }^{2}$ See A. F. Spilhaus, The Transient Condition of the Human Hair as a Hygrometric Element, No. 8 of the Professional Notes of the M.I.T. Meteorological Department. 
continued subsidence warming aloft has really brought about. Consequently the specific humidity appears to increase aloft as subsidence continues. As Namias pointed out in his subsidence investigation, this characteristic sluggishness of the hair hygrometer, most marked at low temperatures, really renders very uncertain what should be our one reliable criterion by which to distinguish between dynamic and advective changes aloft. No other air mass overrunning the $\mathbf{P}_{\mathrm{C}}$ mass could show as low a specific humidity as should be found in the upper levels of the latter air mass. But there are a good many borderline cases where with our present observations it is very difficult to decide whether the lowering of an inversion at high levels, for instance, is due to the advance of a warm dry air mass, or purely to subsidence within the $\mathbf{P}_{\mathrm{C}}$ air mass. Usually the dynamic effects of pure subsidence seem to be manifested in rising pressure (anticyclogenesis) at the ground, and the inflow of a warm air mass above a shallow $\mathbf{P}_{C}$ wedge to be accompanied by pressure fall or even cyclogenesis at the ground. But this is no reliable indication as to what is taking place.

Apart from the cases of subsidence aloft in the $\mathbf{P}_{\mathrm{C}}$ air mass in which a small increase of specific humidity may be indicated, there are a great many cases in which there can be no doubt but that the changes observed at upper levels are caused by the displacement of the $\mathbf{P}_{C}$ by some other air mass. This is the normal case in the south, where most $\mathbf{P}_{C}$ wedges show a very rapid horizontal divergence, and corresponding decrease in depth. In many cases the changes in temperature, specfic humidity, and wind direction with elevation leave no doubt as to what is taking place. The appearance and movement of clouds aloft frequently prove conclusively the occurrence of overrunning. But even in such cases it is often very difficult to locate the upper boundary of the $\mathbf{P}_{C}$ air mass on the cross-section. Such fronts aloft are frequently found to be nearly horizontal, and the transition zone to be quite diffuse. Furthermore, the upper strata of the $\mathbf{P}_{\mathrm{C}}$ mass are usually modified by the air current coming in above, frequently by the evaporation of falling precipitation. But it is not intended at this point to discuss the air mass interactions taking place above the $\mathbf{P}_{\mathrm{C}}$ mass. That is another question reserved for separate consideration. The purpose of this discussion has been to indicate, and to attempt a partial explanation of, the great variability of the $\mathbf{P}_{\mathrm{C}}$ air mass properties which is observed at all levels, and to point out some of the difficulties one is faced with in the interpretation and analysis of cross-sections extending through the upper portions of such masses. Examples of these various analytical complications will be pointed out in the discussion of the individual cross-sections appearing in the last part of this paper.

Assuming that the above discussion of the $\mathbf{T}_{\mathrm{S}}$ and $\mathbf{P}_{\mathrm{C}}$ air masses touches on the most troublesome cases of doubtful air mass identification at upper levels in the United States, we can consider briefly now the air mass interaction or frontal questions listed on p. 8 .

\section{B. Air Mass Interaction Questions}

\section{The Location of the Front Surface in a Transition Zone}

The front surface on a cross-section, as on the surface synoptic chart, is always represented as a single line. Actually the observations show that the transition between two air masses is never a true discontinity, but always in the nature of a zone of finite breadth. The thickness of such a zone may vary from only $100 \mathrm{~m}$, or thereabouts, as in the case of a sharp subsidence inversion, to the very broad continuous warm front transition between fresh $\mathbf{T}_{\mathrm{G}}$ air extending through returning $\mathbf{N}_{\mathrm{PC}}$, to fresh $\mathbf{P}_{\mathrm{C}}$ air. Such a continuous transition zone may be $1000 \mathrm{mi}$. wide on the surface synoptic chart, and ex- 
tend in the vertical through most of the height represented on the usual cross-section. Evidently the placing of the frontal surface or surfaces in such transition zones is quite arbitrary, but in order to have consistent analyses it is necessary to follow some definite convention.

The practice which is most commonly followed, and which has been followed in the M.I.T. synoptic analysis, is to place the frontal surface well on the side of the warmer air mass in the transition zone between two air masses. This has the effect of placing practically the entire transition zone in the colder air mass. It has long been recognized that the Polar air masses are less homogeneous, and more rapidly modified, than the Tropical. This is recognized in synoptic practice by placing the transition zone in the colder air mass. As a result of this practice, on the vertical cross-sections the isopleths of temperature, potential temperature and specific humidity tend to run mostly horizontally throughout the Tropical air masses, as they should in horizontally homogeneous masses. In the Polar air masses the slope of the isopleths which is to be expected in air masses characterized by less horizontal homogeneity, is increased in the transition zones near the air mass boundaries. At the frontal surfaces themselves, although no true discontinuity of the meteorological elements is indicated, there is then usually a marked discontinuity in the slope of the isopleths of these elements, for they mark the boundary between the horizontally homogeneous warmer mass and the beginning of the real transition to the colder mass.

Sometimes on the vertical cross-sections we find cases of marked disagreement between the position of the transition zone as indicated by temperature and the position as indicated by moisture. Such disagreement is usually most marked in the case of sharp temperature inversions which are accompanied by a decrease in moisture. A subsidence inversion sometimes shows a moderate increase in specific humidity just above the temperature inversion, with a very slow decrease at considerably higher levels to the low values which would be expected just above the inversion. This is without question caused by the sluggishness of the hair hygrometer at low temperatures and low relative humidities. ${ }^{1}$ In such cases one must be cautious in making any use of the humidity data. Another similar case is that of the occasional sharp temperature inversion when $\mathbf{T}_{\mathrm{S}}$ air is present above $\mathbf{T}_{\mathrm{G}}$. In this case the moisture decrease is so great that even the sluggish hair always shows the correct tendency of the specific humidity. But doubtless the transition zone is much more abrupt than is indicated by the distribution of specific humidity. Whereas this element may indicate a gradual transition from the moist to the dry air mass extending even a full kilometer above the temperature inversion, actually the moisture transition is probably just as abrupt as that of temperature. This was indicated by the older kite station soundings for which the rate of ascent was much slower than that of the aeroplane. In all cases of temperature inversion with decreasing moisture above, the temperature element is the best one to follow in placing the transition zone and front surface. However, in cases of temperature inversion with increasing moisture above (warm front) this is not necessarily true. Doubtless the sluggishness of the hair hygrometer must be allowed for in this case as well, but it seems frequently to be true that the greatest moisture content of the overrunning warm current may be found well above the level of the highest temperature. This is bound to be true when the warm front shows no temperature inversion aloft, but only diminution of the prevailing lapse rate.

1 See corrected relative humidity curve at temperature inversion as given by A. F. Spilhaus in No. 8 of Professional Notes, M.I.T. Meteorological Department. 


\section{Frontal Structure and Interaction between the Tropical Superior and the Tropical Maritime Air Masses}

We have seen that in the central and southern United States the warm dry $\mathbf{T}_{\mathrm{S}}$ air masses are present a great deal of the time at intermediate and upper levels. Obviously it is very important for purposes of forecasting precipitation both to distinguish carefully between this air mass and the Tropical maritime air masses in all map and cross-section analysis, and to investigate the manner in which these two air mass types may mix or interact with each other: The important difference between the $\mathbf{T}_{\mathrm{S}}$ and $\mathbf{T}_{\mathrm{G}}$ air mass lies in the marked relative dryness of the former mass at all levels. The temperature differences are found to be small, but with the $\mathbf{T}_{\mathrm{S}}$ air mass averaging slightly warmer than the $T_{G}$ at intermediate levels, and tending to be colder at higher levels. This means that as far as density differences are concerned almost any stratification of these two air masses is possible, but that there should be a tendency for $T_{S}$ to overrun $T_{G}$ at low levels, and for $\mathbf{T}_{\mathrm{G}}$ to overrun $\mathbf{T}_{\mathrm{S}}$ at high levels. Actually on the vertical cross-sections we may observe quite a variety of stratification patterns of these two air masses. In summarizing the principal types of this stratification, in order to comment briefly on their synoptic significance, it is advantageous to classify them as occurring in warm sectors, at warm fronts, or at cold fronts. It must be borne in mind that as the total number of crosssections on which this discussion is based is not very large, the stratification patterns mentioned here probably do not exhaust the possibilities, and that any generalizations which may be deduced from these cases are based on rather few observational data. The discussion is based principally on the interaction of the $\mathbf{T}_{S}$ and $\mathbf{T}_{G}$ air masses, for $\mathbf{T}_{G}$ is synoptically the most important of the Tropical maritime air masses in the eastern and central United States. Furthermore, the $T_{A}$ air mass is scarcely to be distinguished from the $\mathbf{T}_{\mathrm{G}}$ mass, and it comes relatively seldom in direct contact with the $\mathbf{T}_{\mathrm{s}}$ air. Special reference is made to the $T_{P}$ air masses in certain cases which seem to warrant it.

(I) The $T_{G}$ and $T_{S}$ stratification patterns in broad warm sectors

In the broad open Tropical air warm sector in the central or southern United States we nearly always find both $\mathbf{T}_{\mathrm{S}}$ and $\mathbf{T}_{\mathrm{M}}$ air present in portions of the warm sector. Nearly always, however, we find mostly $T_{G}\left(T_{M}\right)$ at the ground. Only in exceptional cases, and then only at a considerable distance inland from the $\mathbf{T}_{M}$ source regions (Gulf of Mexico and Sargasso Sea) does the real $\mathbf{T}_{\mathrm{S}}$ air appear at the surface, for at the ground the $\mathbf{T}_{\mathrm{M}}$ mass is almost always the colder mass. The following sketches indicate typical stratification patterns:
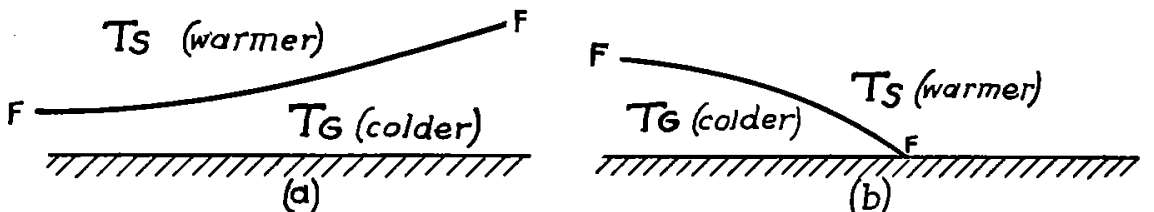

a. This sketch represents the commonest stratification pattern. Shallow $\mathbf{T}_{\mathrm{G}}$ is spread over a wide area, and its upper boundary, usually lying between the $\mathrm{I} \mathrm{km}$ and the $3 \mathrm{~km}$ levels, is marked by a pronounced temperature inversion and a very sharp moisture discontinuity. The slope of the upper boundary is very slight, but the boundary usually 
rises slowly from the southwest Plains states eastward towards the Atlantic coast. There is usually a shift of wind from south towards west associated with the $\mathbf{T}_{G}-\mathbf{T}_{\mathrm{S}}$ boundary. The stratification is usually most pronounced in the south, near the $\mathbf{T}_{\mathrm{M}}$ source region, and in the east, where the $T_{G}$ is relatively deep. In the central Plains states the diurnal heating is usually enough, at least during the warm season, to effect a rather complete convective dissipation of the shallow $\mathbf{T}_{\mathrm{G}}$ stratum during the afternoon. The resulting mixed stratum remains too dry, however, for convective showers to occur.

The synoptic significance of this very typical $\mathbf{T}_{\mathrm{S}}-\mathbf{T}_{\mathrm{G}}$ stratification pattern lies in the impossibility of convective shower and thunderstorm formation, even in summer. The warmth and extremely high moisture content of the lower $\mathbf{T}_{\mathrm{G}}$ stratum would lead one to expect, from surface observations alone, the appearance of afternoon thunderstorms. But in spite of the convective instability indicated by a very large decrease in equivalent potential temperature with elevation, the thermal stratification and the shallowness of the moisture-laden air is enough to prevent the realization of this potential convective energy. About $3 \frac{1}{2} \mathrm{~km}$ seems to be the usual minimum depth of the $\mathbf{T}_{G}$ air mass required in cases of this type of stratification in order for convective thunderstorms to develop during the day. As we shall see presently, even the advance of a cold front into a warm sector stratified in this way does not produce frontal showers unless the moist $\mathbf{T}_{\mathrm{G}}$ stratum is extended vertically ahead of the cold front at least to some such depth as that.

A good illustration of this type of $\mathbf{T}_{\mathrm{G}}-\mathbf{T}_{\mathrm{S}}$ stratification will be found on section $\mathrm{C}$ for Jan. 15, I932 (Plate XIII).

b. This sketch represents a special case of the same type of stratification represented in a. In this case the $T_{G}$ is advancing as a typical shallow cold air wedge under the warmer $\mathbf{T}_{\mathrm{S}}$ air mass. Usually such lifting of the dry $\mathbf{T}_{\mathrm{S}}$ air has no thermodynamic consequences. Showers occur only in the exceptional case that the $\mathbf{T}_{\mathrm{G}}$ wedge is quite deep, so that vigorous convection is started in the lower air mass. In that case, however, probably some of the potential convective energy present owing to the comparatively low equivalent potential temperature of the upper dry stratum may be realized. But in my experience with cross-sections I have found as yet no case of shower formation in the type of stratification represented in $b$.

This may be due in part to the fact that I have no cross-sections for the months June through September, which is the season most favorable to the formation of convective showers over land. A good instance of this type of $\mathbf{T}_{\mathrm{G}}-\mathbf{T}_{\mathrm{S}}$ stratification, without shower formation, is to be found on section C, for Jan. I4, I932 (Plate XI).

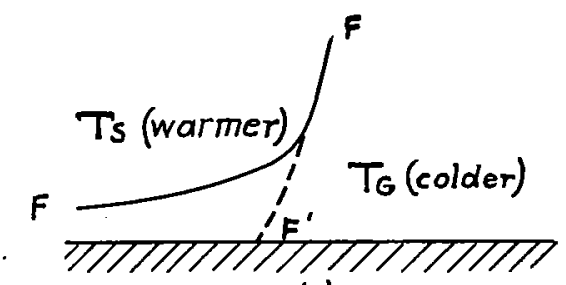

(c)

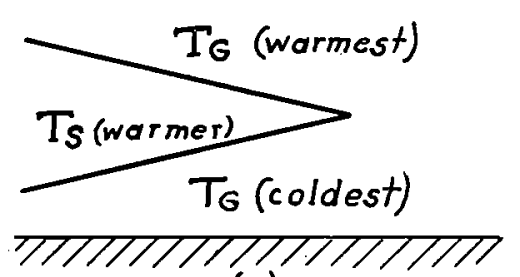

(d)

c. This sketch represents the case of a very steep front between the $\mathbf{T}_{\mathrm{G}}$ and $\mathbf{T}_{\mathrm{S}}$ air masses. This stratification type is relatively infrequent, and it occurs only when the temperature difference between the air masses is small. We may find the steep front extending directly upward from the ground, as represented by $F F^{\prime}$, or with the $\mathbf{T}_{\mathrm{S}}$ mass overlying a 
shallow wedge of $\mathbf{T}_{\mathrm{G}}$, as shown by the line $F F$. In some cases the boundary surface $F F^{\prime}$ seems to be nearly vertical, but the temperature contrast is so small that the front has little dynamic significance. It is seldom that such a steep front is penetrated by an aerological sounding, and in no case as yet has it been possible actually to establish the slope of such a front through its penetration by two soundings. In this case the principal synoptic significance of such a steep front lies in the sharp demarcation which it fixes between regions of some cloudiness and convective showers or thunderstorms, and regions of cloudless skies and dry air. Such lines of demarcation or steep $\mathbf{T}_{\mathrm{G}}-\mathbf{T}_{\mathrm{S}}$ fronts occur mostly in summer, in the southwest, and usually advance with the $\mathbf{T}_{\mathrm{s}}$ current like any other front. However, owing to the small temperature contrast and wind shift usually accompanying this type of front, it frequently escapes detection, and the reason for the cessation of thunderstorms in a given area is likely to be missed. Their occurrence has nothing to do with the front, but depends only on the depth and stability of the $\mathbf{T}_{\mathrm{G}}$ air mass, which as we have seen requires a depth in excess of $3 \mathrm{~km}$ to be effectively productive of thunderstorms.

d. This sketch represents a stratification which is very common during the summer in the southwest, where a warm dry stratum of air with a more westerly component penetrates at intermediate levels into the moister $T_{G}$ current which moves more from the south. The mechanism of this type of current stratification is hard to explain, but at least it corresponds to the vertical temperature distribution. The lower $\mathbf{T}_{\mathrm{G}}-\mathbf{T}_{\mathrm{S}}$ boundary is usually characterized by a well marked temperature inversion, and the upper $\mathbf{T}_{\mathrm{S}}-\mathbf{T}_{\mathrm{G}}$ boundary by pronounced thermal stability. Mechanical and convective turbulence, especially during the summer afternoons, lead to the gradual dissipation by mixing of the dry stratum both to the east and to the north of the region of formation, which is most frequently the Texas-Oklahoma section. It is most sharply marked in the morning, especially at the lower boundary, where a specific humidity decrease from $\mathrm{I} 7 \mathrm{~g}$ to $4 \mathrm{~g}$ may occur in only a few hundred metres. As the author has already pointed out, ${ }^{1}$ this type of stratification is observed to be quite pronounced at Groesbeck, Tex., in about $40 \%$ of the summer soundings when $T_{G}$ air prevails at the ground at that station. A good illustration will be found on section B for Oct. 15, 1933 (Plate XXIV). In this case the tendency of the dry layer to be dissipated further from the Gulf is clearly shown by differences between Dallas and Omaha. The only synoptic significance of such a stratification lies in the markedly damping effect it must have on the establishment of thunderstorm convection in cases where the $T_{G}$ air really extends to high levels. The effectiveness of this damping influence will depend on the thickness of the dry layer, and the degree to which it is marked by thermal stratification.

(2) $T_{G}$ and $T_{S}$ stratification patterns above warm fronts

The $T_{G}-T_{S}$ stratification is less marked and seems to be of less synoptic significance at warm fronts than it is within the warm sector. This is indicated both on the crosssections and by the fact that even marked stratification of the $T_{G}$ air in the warm sector does not necessarily prevent the occurrence of heavy precipitation at the warm front. This is due partly to the observed fact that the moist $\mathbf{T}_{\mathrm{G}}$ shows a well-marked tendency to deepen in the foremost portion of the warm sector, close to the warm front. This deepening must be the result in some way of the action occurring at the front. It implies

${ }^{1}$ H. C. Willett, American Air Mass Properties. 
that horizontal convergence is taking place in the warm air mass, and will normally entail a steepening of the lapse rate and dissipation of temperature inversions. But even. more important than this deepening effect in overcoming the $\mathbf{T}_{\mathrm{S}}$ stratification at the warm front is the effect of the lifting of the stratified Tropical air above the warm front. Byers $^{1}$ has recently investigated the effect on the overrunning air mass of the lifting at a warm front. He finds strong observational evidence to the effect that the overrunning warm current undergoes marked horizontal divergence, amounting to about $20 \%$ per IOO mb of lifting. As Byers points out, the effect of such divergence must be to decrease the lapse rate in the warm current, unless the air stratum being lifted is convectively unstable and saturated. Thus in the case of a dry $\mathbf{T}_{\mathrm{S}}$ stratum overlying moist $\mathbf{T}_{\mathrm{G}}$, above the condensation level of the moist $\mathbf{T}_{\mathrm{G}}$ the natural tendency of lifting to steepen the lapse rate will be accelerated by the realization of the convective instability inherent in such a stratification pattern, i.e., in the decrease of equivalent potential temperature observed in passing from the moist to the dry air. According to Byers such a steepening of the lapse rate is usually observed above warm fronts. It is not strange, then, between the initial deepening of the moist air, and the lifting and attendant dissipation of the entire stratification pattern above the warm front, that the $\mathbf{T}_{\mathrm{G}}-\mathbf{T}_{\mathrm{S}}$ stratification appears less frequently and is less marked above the warm front than elsewhere on the crosssections, and that fairly heavy precipitation of the convective type may occur at the warm front even when in most of the warm sector we find marked stratification.

Occasionally, however, the stratification above the warm front remains quite clear. In these cases it doubtless exerts a depressive, if not a prohibitive, influence on the occurrence of precipitation. The following two sketches show observed stratification patterns above warm fronts:

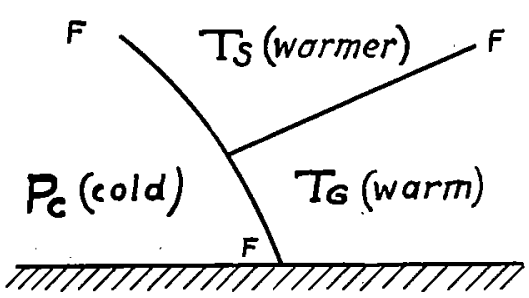

(a)

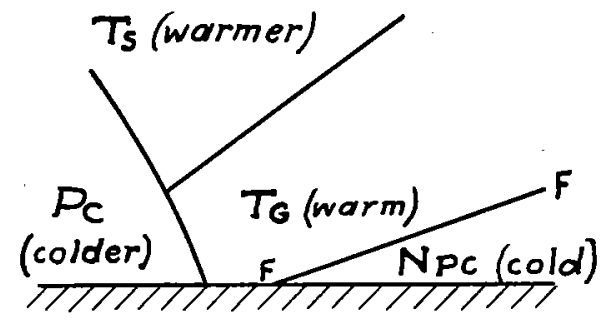

(b)

a. This sketch shows the usual stratification with the warm dry $\mathbf{T}_{\mathrm{S}}$ above the somewhat cooler moist $T_{G}$. An illustration of this type will be found on cross-section $A$ for Jan. I 2, I 932 (Plate VII). In this case the precipitation was widespread but light.

b. This type of stratification occurs occasionally when the $\mathbf{T}_{\mathrm{G}}-\mathbf{T}_{\mathrm{S}}$ temperature difference is small. An illustration will be found on section A for Oct. I5, I933 (Plate XXIV). In this case also the precipitation was light.

(3) $T_{G}$ and $T_{S}$ stratification patterns above cold fronts

It is above the cold fronts that we find the greatest variety of $\mathbf{T}_{\mathrm{G}}-\mathbf{T}_{\mathrm{S}}$ stratification patterns, and where we find the clearest control of the amount of frontal precipitation by the type of stratification. The movement of air above the cold front is normally descending along the front surface. This descending movement results in an increasing stratification of the warm air above a cold front, unless the descending movement is

1 The Changes in Air Masses during Lifting, as yet unpublished. 
accompanied by marked horizontal convergence. But even in this event the lapse rate can be steepened only within the descending current, while the stratification between the descending current and lower air strata at rest is increased. Thus the normal occurrence of a descending movement in the warm air above a cold front tends to increase the temperature and moisture stratification between the warm air masses at the front. This condition is just the reverse of that found to hold for the warm front. Byers, in the paper referred to above, finds direct observational evidence which confirms the correctness of this hypothesis. This is doubtless the explanation of the large number of cold fronts whose passage, in the absence of favoring orographical conditions, is attended either by no precipitation at all or at most by only light prefrontal showers. This condition is represented by the stratification patterns $a$ and $b$ below. However, it sometimes happens that the $\mathbf{T}_{\mathrm{S}}$ current (or perhaps in some cases $\mathbf{N}_{\mathbf{P P}}$ ) descending along the cold front is colder than the $\mathbf{T}_{G}$ at the same levels. In that case the $\mathbf{T}_{\mathbb{S}}$ may advance aloft as an upper cold front (sketch $c$ ), or actually overrun the warmer $T_{G}$, if the temperature difference is small (sketch d). In this latter case very heavy convective precipitation may occur. There is one more general type of development which may take place above the cold front, and that is for the $\mathbf{T}_{\mathrm{G}}$ mass to deepen and completely displace the dry descending current above the cold wedge. Apparently this may result either from active convection and horizontal divergence aloft in the $T_{G}$ mass, or from a general ascent, with horizontal divergence, of the warm air above a slowly moving cold wedge, i.e., practically the transformation of the cold front to a warm front. This type of stratification pattern is represented in sketch e below.

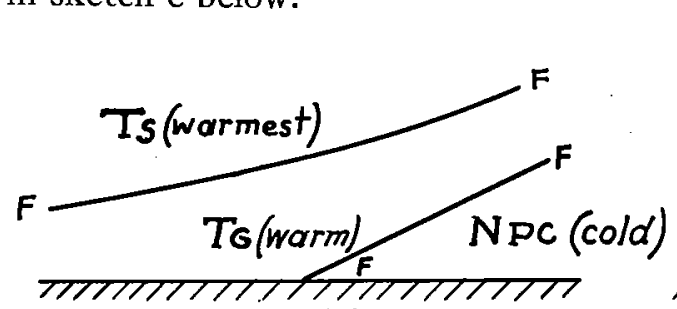

(a)

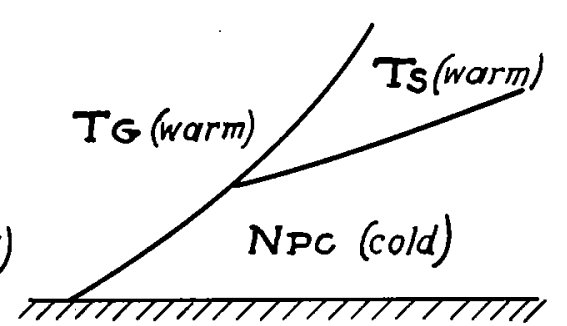

(b)

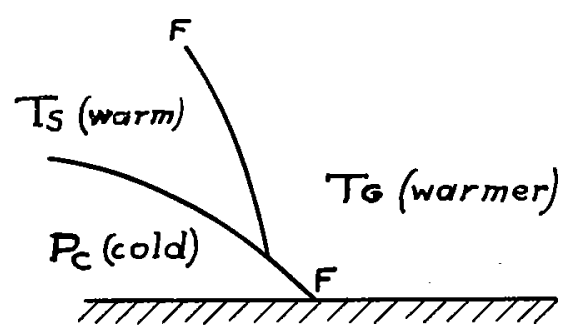

(c)

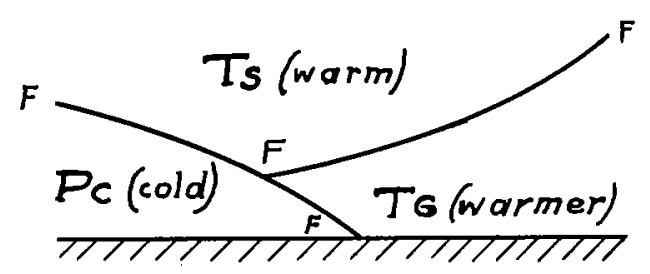

(d)

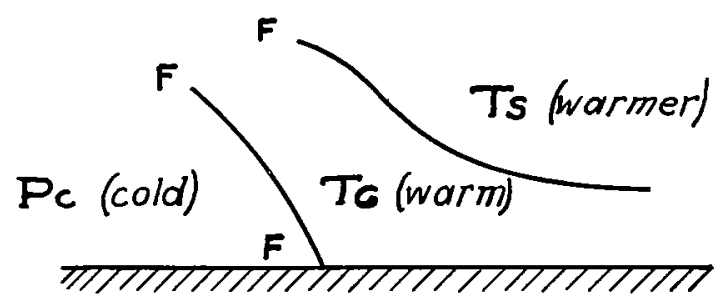

(e) 
Sketches $\mathrm{a}$ and $\mathrm{b}$ above represent the commonest cold front stratification pattern in the central and southern United States. The $T_{S}$ aloft apparently is descending along the upper boundary of the cold wedge, and moving much more from the west than the northward moving surface $T_{G}$ current. It is this frequently observed shift of wind to the west above a shallow surface southerly current which has led to the common assumption in this country that the cold $\mathbf{P}_{\mathrm{C}}$ air may advance great distances aloft above the surface warm air mass. Actually, however, this overrunning current is quite another air mass than the $\mathbf{P}_{C}$, and it is usually warmer than the $\mathbf{T}_{G}$ at the same level. The resulting stable stratification in the warm air above and ahead of the cold front is increased by the downward movement of the $\mathbf{T}_{\mathrm{S}}$ current along the cold front surface. Consequently this commonest cold front type is either rainless, or at most accompanied by moderate prefrontal showers with clearing upon the passage of the front, depending upon the depth of the $T_{G}$ air. Cross-sections A, B, and C for Jan. I 5, I932, (Plates XII and XIII), represent almost ideal cases of this type of stratification. On section $A$ we find the moist $\mathbf{T}_{\mathrm{G}}$ ahead of the cold front exceeding the critical $3 \frac{1}{2} \mathrm{~km}$ depth (p. 18 ), and along this portion of the front moderate prefrontal thunderstorms are occurring. On sections $\mathrm{B}$ and $\mathrm{C}$ the moist $\mathbf{T}_{\mathrm{G}}$ is found to be less than $3 \mathrm{~km}$ deep ahead of the cold front, and no precipitation is falling.

Sometimes it happens that the westerly current above the cold wedge is slightly colder than the $\mathbf{T}_{\mathrm{G}}$ air in the warm sector at the same level. This may occur in the case of a $T_{\mathrm{S}}$ current returning from higher latitudes, or it is possible that at times this dry upper current is not $\mathbf{T}_{\mathrm{S}}$ at all, but perhaps greatly modified $\mathbf{N}_{\mathrm{PP}}$. As we have already seen, it is not always possible to identify with certainty the upper limit of the Polar air cold wedge, and the same thing is sometimes true about the identification of the air strata just above the Polar air mass. But even in these cases of doubtful identity of the $\mathbf{T}_{\mathrm{s}}$ current above the cold front, there is no possiblity of confusing this current with the surface air mass of the true cold wedge, which never advances aloft any appreciable distance ahead of the cold front at the ground. The temperature of the upper current is always very near that of the $T_{G}$ at the same level.

In these exceptional cases when the $\mathbf{T}_{\mathrm{S}}$ current above the cold wedge is slightly colder than the $T_{G}$ air mass at the same level, the $\mathbf{T}_{\mathrm{S}}$ air mass may advance as an upper cold front, or if the temperature difference is small, it may actually overrun the warmer surface $T_{G}$ air. Sketches $c$ and $d$ represent these two possibilities. Sketch $c$ shows the normal stratification when the $\mathbf{T}_{\mathrm{S}}$ is, level for level, equal in temperature to the $\mathbf{T}_{\mathrm{G}}$, or slightly colder. The much smaller moisture content of the $\mathbf{T}_{\mathrm{S}}$ air makes it slightly denser than the $\mathbf{T}_{\mathrm{G}}$ at the same temperature and pressure. The net effect of the $\mathbf{T}_{\mathrm{S}}$ air in this case is to advance the position and steepen the slope of the effective cold front at upper levels. Prefrontal and front passage showers normally occur with this type of cold front, for the convectively unstable $T_{G}$ is not bounded aloft by the usual warm dry $T_{S}$ stratum. A good instance of this type of stratification is found on section B for Oct. I4, I933 (Plate XXII). In this case the cold mass is only $\mathbf{N}_{\mathrm{TP}}$, but it is markedly colder and somewhat drier than the $\mathbf{T}_{\mathrm{G}}$, and markedly colder and moister than the $\mathbf{T}_{\mathrm{S}}$ above it. In fact, up to about $\mathrm{I} \frac{1}{2}$ $\mathrm{km}$ the $\mathbf{T}_{\mathrm{S}}$ is warmer than the $\mathbf{T}_{\mathrm{G}}$, but above that level it becomes gradually slightly colder. The result is that we find an overrunning wedge of $\mathbf{T}_{\mathrm{S}}$ which shows up clearly on the Dallas ascent. It reaches its most advanced position at the $1 \frac{1}{2} \mathrm{~km}$ level while above this level we find a reversal of the slope of the $T_{S}$ front as it changes from a warm to a cold front slope. Actually, however, in this cross section the lower portion of the $\mathbf{T}_{\mathrm{S}}$ front is indicated as cold, the upper portion as warm, for these fronts are just on the point of 
reversing their movement as the $T_{G}$ air mass begins to advance against the $T_{S}$. The $\mathbf{N}_{\mathrm{TP}}$ cold front has become stationary.

Sketch $d$ represents the cold front structure in the unusual case when the $\mathbf{T}_{\mathrm{S}}$ air mass overruns the $T_{G}$ even though it is slightly the colder air mass. Why this should occasionally occur is not clear. It happens only when the temperature difference between the two air masses is quite small. Obviously the result is a markedly unstable stratification, with a lapse rate well in excess of the saturation adiabatic. But a super dry-adiabatic lapse rate is not produced in this way, as far as my observations go. In all the thousands of aerological soundings which I have studied, I have yet to find a single authentic case of a lapse rate at upper levels in excess of the dry adiabatic, produced by the overrunning of a warm by a cold air mass. Superadiabatic lapse rates extend from the ground upward in special cases of marked surface influence. If the cold Polar air masses really do at times advance hundreds of miles ahead of the position of the cold front at the ground, as is frequently claimed, then superadiabatic lapse rates would occasionally be observed in winter at upper levels ahead of cold fronts.

A good illustration of the cold front structure represented by sketch $\mathrm{d}$ will be found on cross-section C for January I2, I932 (Plate VII). The steep lapse rate indicated aloft between Dallas and Pensacola is striking. In this case extremely heavy prefrontal and front passage thunderstorms occurred.

Sketch e represents the case in which the moist $\mathbf{T}_{\mathrm{G}}$ air mass deepens rapidly over the $P_{C}$ cold wedge, completely displacing the dry $\mathbf{T}_{\mathrm{S}}$ air mass aloft. An explanation of why this occurs in some cases and not in others is impossible to offer at present. It must in each case be the result of the general dynamic state of the whole interacting system of air masses. However, it seems to take place in two distinct ways, though both lead to the same stratification pattern as represented by e. Apparently in one case the deepening of the $\mathbf{T}_{G}$ ahead of and above the $\mathbf{P}_{C}$ wedge is the result simply of active prefrontal convection in the moist $\mathbf{T}_{\mathrm{G}}$ air, with its attendant horizontal convergence at low levels, and horizontal divergence at upper levels. This type of deepening occurs when the cold front is advancing steadily, and presumably in the absence of a strong descending $\mathbf{T}_{\mathrm{s}}$ current above the wedge. It appears as though it were just the dynamic effect of the crowding of the $\mathbf{T}_{\mathrm{G}}$ air by the advancing cold wedge, in the absence of the usual strong stabilizing $\mathbf{T}_{\mathrm{S}}$ current aloft. It is to be noted, however, that in this case of the rapidly advancing cold front the rising $\mathbf{T}_{\mathrm{G}}$ air does not ascend the cold front surface to any great distance behind the cold front at the ground. Precipitation does not fall to any great distance behind the cold front, so that it is not of very great duration. Clearing follows quickly on the passage of the cold front. But this type of cold front is nearly always accompanied by convective showers, of moderate to heavy intensity. A good illustration of this type of cold front action, will be found on cross-section A, for Oct. I7, I933 (Plate XXVII). In this case a sequence of three soundings at Boston just ahead of the cold front show very well the structure of the deepening moist $T_{G}$ stratum. The great irregularity met with from point to point in these soundings, together with the cloud forms, show clearly the irregular convective deepening of this $T_{G}$ stratum. Moderately heavy showers accompanied the cold front passage in this case. It will be noted that the moist $\mathbf{T}_{G}$ stratum exceeded the critical $3 \frac{1}{2} \mathrm{~km}$ depth only a short distance ahead of the cold front. Precipitation also set in only a short distance ahead of the cold front.

The other set of conditions leading to the cold front structure represented by e, occurs when an advancing well-marked cold front slows down in its movement, and becomes 
stationary. In this case it frequently happens that the $\mathbf{T}_{\mathrm{S}}$ current aloft also ceases, and the moist $\mathbf{T}_{\mathrm{G}}$ stratum begins to ascend the cold front surface on a large scale, and to deepen rapidly. In other words, although we may retain even a slow advance of the cold front at the ground, all the frontal action becomes that of an active warm front. The ascending $\mathbf{T}_{G}$ stratum deepens and becomes increasingly unstable, and heavy widespread precipitation sets in behind the cold front. It is this condition which frequently leads to blizzard conditions in winter in the central and southern Plains states, following a marked outbreak of cold $\mathbf{P}_{\mathrm{C}}$ air, after the rate of advance of the cold wedge becomes markedly slowed down. No satisfactory explanation can as yet be offered for the reason of this reversal of the air flow above the cold wedge in certain cases. An excellent illustration will be found on cross-section C for Jan. I5 and Jan. I6, I932 (Plates XIII and XV). On the section for Jan. I 5 we find the stable $\mathbf{T}_{\mathrm{S}}$ stratification typical of the advancing cold front, as represented in sketch a. However, a comparison of the surface map for this day with that of the preceding day (Plates X and XII) shows that the front is now advancing very slowly. From the surface map for Jan. I6 (Plate XIV) we see that the cold front has advanced very little further, but a glance at the cross-section shows that a complete transformation has occurred at upper levels from a cold front of type a to one of type e. The moist $T_{G}$ air now extends to at least $6 \mathrm{~km}$, and heavy precipitation of the warm front type has set in to a great distance behind the cold front.

\section{Air Mass Interactions Occurring above Extensive Surface Cold Polar Air Masses}

In the discussion of the vertical structure of the American $\mathbf{P}_{\mathbf{C}}$ air masses, it was noted that although it is sometimes difficult to distinguish between the upper air mass strata of true $\mathbf{P}_{\mathrm{C}}$ origin and overrunning currents from an entirely different source region, nevertheless there are numerous cases of the occurrence of pronounced changes above extensive shallow $\mathbf{P}_{\mathrm{C}}$ masses which without question are associated with the interaction of other air masses aloft. It is of interest to consider briefly a few of the possibilities of this type of interaction at upper levels, in which the surface cold air mass remains quite passive. The illustrative material from the cross-sections is rather scanty, however, for the accompanying meteorological action at the surface is seldom very pronounced. Consequently such periods during which the principal action occurs at upper levels are likely to be overlooked in the selection of situations for cross-sectional analysis.

There are three particular cases of this upper level activity which seem to require special mention here.

a. The simplest case is that of the rapid eastward advance of a warm air mass from the Pacific, following a deep $\mathbf{P}_{\mathrm{C}}$ outbreak east of the Rocky Mountains. When this occurs the warm air mass, usually $\mathbf{T}_{\mathrm{S}}$ or $\mathbf{N}_{\mathrm{TP}}$, advances eastward above the tops of the Rocky Mountains, with a very diffuse and nearly horizontal warm front. If the overrunning air mass is $\mathbf{T}_{\mathrm{S}}$ the sky remains cloudless, if it is $\mathbf{N}_{\mathrm{TP}}$ there may be scattered high clouds, but seldom any precipitation. This probably follows from the fact that even the $\mathbf{N}_{\text {TP }}$ is relatively dry after crossing the western mountain ranges and the fact that the lifting of the overrunning current is small in amount and takes place slowly. The principal effect noted aloft in this case of simple advection is a marked rise in temperature first in the west at the uppermost levels of observation, and then at successively lower levels and further to the east as the warm current works lower and advances rapidly. But usually east of the Rockies a fairly deep layer of cold $\mathbf{P}_{\mathrm{C}}$ or $\mathbf{N}_{\mathrm{PC}}$ remains at the ground until other developments occur. Ordinarily the only noticeable effects at the ground of this type of 
upper level warm air advection is a steady, frequently rapid, moderation of the low temperatures in the cold $\mathbf{P}_{\mathrm{C}}$ air mass, and usually an appreciable pressure fall or weakening of anticyclonic pressure gradients.

This displacement of the upper strata of a deep cold $\mathbf{P}_{\mathrm{C}}$ air mass by the rapid advection of a warmer air mass is especially liable to confusion with subsidence aloft. But there are two fairly good checks to be applied in any doubtful case. One lies in the surface pressure changes. Active subsidence in a deep cold $\mathbf{P}_{\mathrm{C}}$ mass nearly always is accompanied by active anticyclogenesis at the ground, this advective effect by the weakening of the anticyclonic pressure gradients. The other check lies in the moisture changes which accompany the temperature changes aloft. Even though the sluggishness of the hair hygrometer may cause an apparent increase in specific humidity at the subsidence inversion, this increase must give way to a decrease at least by the time the same temperature is reached above the inversion as is observed just below it. But in the case of the overrunning warm current, the increase in specific humidity is much greater, and it persists to a much greater distance above the inversion, than in the case of subsidence. When the specific humidity above the inversion is found to be greater than that below the inversion even up to an elevation where the temperature is markedly lower than that found just below the inversion, then there can be no doubt that the phenomenon observed is one of advection rather than subsidence, and the cross-section analysis must show a warm front and a warm air mass.

Cross-sections A for Dec. 6, 7, and 8, I93I (Plates II, III, and V) show a good example of the rapid eastward spread of such a relatively warm and moist current of $\mathbf{N}_{\mathrm{TP}}$ above a deep cold $\mathbf{N}_{\mathrm{PP}}$ air mass. On the sixth the warm current had not yet appeared at the top of the ascent at Omaha, which had only recently been passed by the $\mathbf{N}_{P P}$ cold front. During the next two days the warm current began to make its influence felt aloft about 24 hours behind the advancing cold front.

b. Another similar but somewhat more complicated case is the one in which, instead of a single overrunning relatively warm air mass from the Pacific, we find aloft two such air masses or adjacent currents, one of Tropical Pacific and the other of Polar Pacific origin. In this case, which occurs rather frequently in winter above horizontally extensive but shallow $\mathbf{P}_{\mathrm{C}}$ masses, there must be an upper front between the Tropical Pacific current to the south and the Polar Pacific current to the north. Occasionally what appear to be quite pronounced waves develop on such an upper front and travel rapidly eastward, attended by rather widespread and sometimes moderately heavy precipitation at the ground. Such an area of precipitation, usually snow, appears first in the Rocky Mountain region and may advance eastward across the country to the Atlantic seaboard within thirty-six hours. Although cold $\mathbf{P}_{\mathrm{C}}$ air remains at the ground throughout such an upper level disturbance, the pressure changes aloft are naturally reflected at the surface in falling pressure in the precipitation area (upper warm front) followed by a marked pressure rise (upper cold front). Such a disturbance in the surface pressure field naturally induces a corresponding surface wind distribution within the cold air mass, southerly winds in front, northerly winds behind. This leads to a certain amount of frontogenesis within the latitudinally non-homogeneous surface $\mathbf{P}_{\mathrm{C}}$ air mass, and the appearance of what might be called an induced surface warm sector and cold sector. Such surface frontogenesis within the cold air mass corresponding to upper warm and cold fronts may best be indicated on the synoptic charts as broken warm and cold fronts. A good instance of this type of development is to be found on the weather maps of Dec. I2-I4, 1933. 
Unfortunately there was insufficient aerological data to prepare any cross-sections for this case. This is likely to be true of those winter phenomena characterized by widespread snowfall and marked cold. Another difficulty in tracing such upper level phenomena lies in the fact that they can be only indirectly observed at the surface, while at upper levels they cannot be observed successfully with any continuity from day to day on the same cross-section, because they usually have a considerable component of their movement directed across rather than along the cross-section. Consequently we do not view sections through corresponding parts of the disturbance from one day to the next. An obvious case of upper level interaction of this type, between $\mathbf{N}_{\text {PP }}$ and $\mathbf{N}_{\text {TP }}$ air masses, appears on the cross-sections for Jan. I4 and I 5, I932. It can be seen most clearly on the two B sections for these two days, although it is not an ideal case (Plates XI and XIII).

c. A third significant case in which a warm current may advance great distances at upper levels above a shallow Polar air mass occurs occasionally in the eastern United States with $\mathbf{T}_{\mathrm{G}}$ (or $\mathbf{T}_{\mathrm{A}}$ ) as the overrunning air mass. This happens most frequently with a quasi-stationary $T_{G}$ warm front located not far north of the Gulf coast, and is usually accompanied by a moderate wave disturbance which passes eastward along the $\mathbf{T}_{\mathrm{G}}-\mathbf{P}_{\mathrm{C}}$ front. Although the warm front may advance only a short distance northward, the $\mathbf{T}_{\mathrm{G}}$ current at upper levels may be traced as far as the Gulf of St. Lawrence or even the coast of Labrador. Such a very extended advance of the $T_{G}$ current aloft is usually attended by widespread cloudiness and moderate rain, but ordinarily the slope of the upper $\mathbf{T}_{\mathrm{G}}$ warm front does not seem to be steep enough to cause the precipitation to be very heavy. The advance of such an upper front is frequently clearly reflected at the ground by the pressure tendencies, pressure distribution, wind discontinuity, and distribution of precipitation, while the temperature in the surface $\mathbf{P}_{C}$ air mass remains almost unchanged. On other occasions there is no clearly marked upper front, but the surface pressure falls at the ground throughout the region being overrun by the warm air, so that the surface isobars show a trough shaped depression extending northeastward from the $\mathbf{T}_{\mathrm{G}}$ warm front through the Polar air. Frontogenesis, and frequently the formation of a separate center of low pressure somewhere in the St. Lawrence Valley may occur within the cold air mass under these conditions. The synoptic significance of such a development lies in the effect of the secondary depression in the northeast on the pressure field. If that development is not anticipated, strong northeast winds are likely to be forecast for the middle and north Atlantic coast, in the expectation that the eastward moving wave on the $T_{G}$ front will move off the coast and occlude rapidly, causing a disturbance of marked intensity on the coast. But actually what happens is that the secondary disturbance developing in the north greatly weakens or even reverses the pressure gradient along the coast, so that instead of strong northeast winds moderate south or southeast occur. At the same time the wave disturbance on the $\mathbf{T}_{G}$ warm front, instead of occluding and intensifying, is likely to peter out entirely because of the shallowness of the cold air mass and consequent small slope of the warm front. Unfortunately there is no illustration of a development of this type among the cross-sections available for this paper. However, anyone who is interested may find a typical case of such a development on the synoptic charts for May 5-6, 1935 (not included in this publication).

Of course, there are many other possibilities of the extended movement or interaction of different air masses above an extensive surface Polar air mass. The three particular types of such development chosen for discussion here were selected because of their 
synoptic significance, their frequency of occurrence, and their typically outstanding characteristics.

\section{The Polar-Tropical Air Mass Contrasts, and the Variation with Elevation of the Sharpness of the Fronts between Them}

The question of the intensification or disappearance with increasing elevation of surface frontal discontinuities is one of considerable synoptic significance. The intensity of the frontal phenomena and the tendency toward the development of disturbances on the front both depend on the intensity and slope of the front. Usually the steeper fronts are also the sharper fronts. The abruptness of the wind discontinuity which must accompany a steep front tends automatically to produce and maintain an abrupt transition in the other meteorological elements. But the total temperature or moisture difference across the frontal transition zone, and consequently also the intensity of the discontinuity depend at each level upon the difference in the values of these two elements in the two air masses at the same elevation. Since the slope of a warm or cold front usually decreases with increasing elevation above the ground, it is clear that unless the contrast in the properties of the two air masses separated by the front in question increases with elevation, the intensity of the frontal discontinuity will tend to decrease with elevation, and the synoptic and dynamic significance of the front will be less than is indicated by the surface observations. In cases where the air mass contrast increases with elevation, the reverse will normally be true.

In general the sharpness of the warm front discontinuity between the Tropical and the Polar air masses varies much less than does that of the cold front. This is largely the result of the fact that the warm front slope is much less steep and more uniform at all levels than that of the cold front, and that the warm front is normally much more diffuse than the cold front. The air mass contrast between the advanced cooled portion of the Tropical air current and the prefrontal $\mathbf{N}_{P C}$ or $\mathbf{N}_{\text {PP }}$ air is relatively small and constant with elevation when compared with that between the fresh Polar and fresh Tropical air masses at the cold front. The relatively small slope, the diffuseness, and the constancy with elevation of the warm front all combine to minimize the significance of its variations with elevation for either synoptic or dynamic considerations. It is only in the case of the cold front between the Polar and Tropical air masses that changes in the front with elevation seem to merit some brief consideration.

Since the $\mathbf{P}_{\mathrm{C}}$ and $\mathbf{N}_{\mathbf{P C}}$ cold air wedges, as we have already seen, are frequently characterized by extreme thermal stratification and increase of moisture aloft, whereas the $T_{G}$ air mass is normally characterized by a moderate lapse rate and a slow decrease of moisture throughout its vertical extent, the intensity of the surface cold front between two such air masses is bound to decrease with elevation at least up to the height of maximum warmth and moisture of the cold air mass. In cases where the $\mathbf{T}_{G}$ mass is of only limited depth with the warm dry $\mathbf{T}_{\mathrm{s}}$ appearing aloft, the relationship is little changed, for the thermal stratification in the warm sector is even then very slight compared with that in the cold wedge. In such cases, however, the normal moisture contrast at the cold front may actually be reversed, the moisture content of the upper levels of the cold air wedge may be double that in the $T_{\mathrm{S}}$ air at the same levels in the warm sector. In these cases of extreme warmth and high moisture content in the upper levels of the cold wedge, which are presumably nearly always cases in which the upper portions of the cold wedge 
are composed of air masses of recent Pacific origin, we may find frontal temperature contrasts of $20^{\circ}$ or even $30^{\circ} \mathrm{C}$ at the ground reduced to $10^{\circ} \mathrm{C}$ or even less from as low as the $2 \frac{1}{2} \mathrm{~km}$ level upwards. If the warm sector is composed of $T_{G}$ air throughout, the contrast in moisture content may change from a 20 to $I$ ratio between the $T_{G}$ and $P_{C}$ air masses near the ground to a 2 to I ratio near the $3 \mathrm{~km}$ level. If the warm sector at the $3 \mathrm{~km}$ level is composed of $\mathbf{T}_{\mathrm{S}}$ air, we may even observe the reverse $\mathrm{I}$ to 2 ratio. It is the occurrence of conditions such as these which frequently makes the definition of the upper limits of the cold wedge somewhat questionable. Thus a cold front which is very pronounced at the surface may become so diffuse at upper levels that even its location is open to question.

This type of phenomenon is of considerable synoptic significance from the forecaster's point of view. This type of cold front always is associated with the dying-out type of cold wave. The movement of the front is usually rather slow, and the foremost portion of the shallow surface layer of cold air tends to be very rapidly modified. The result is that what at first appears to be a threatening severe cold wave in the northwest, as judged by the high pressure and very low temperatures at the ground, peters out very rapidly as it moves eastward. By the time the eastern United States is reached, it is likely to have become a very mild affair. The cold-wave anticyclone for the most part vanishes, and the temperature may drop not even to the seasonal normal with the cold front passage. The occurrence of precipitation with the cold front passage depends upon the depth of the $\mathbf{T}_{G}$ air at each portion of the front, i.e., whether the typical $\mathbf{T}_{\mathbf{S}}$ stratification is present at intermediate levels. Another characteristic of this type of cold front is that its southward advance is likely to diminish, so that it becomes stationary in the southern portion of the country. When this happens it is likely to be transformed into an active warm front with a renewed northward advance of the $T_{G}$ air mass aloft and the occurrence of widespread precipitation in central and northern portions of the country.

An excellent example of a cold wedge of complicated vertical structure and of a pronounced surface air mass contrast which decrease rapidly with elevation is shown in sections A and B for Jan. I4 and I 5, I932 (Plate X ff.). In this case also sections B and C for Jan. I 5 and $I 6$ show the typical retardation of the cold front advance in the South and and the beginning of its transformation to an active warm front.

In the discussion of the vertical structure of the $\mathbf{P}_{\mathbf{C}}$ cold wedges it was pointed out (p. 13) that occasionally, in the central and eastern United States, the $\mathbf{P}_{\mathbf{C}}$ air masses are relatively homogeneous, being extremely cold and dry throughout their vertical extent, at least as high as the aeroplane soundings extend. In such cases the air mass contrast at the $\mathbf{P}_{\mathrm{C}}$ cold front remains constant or even increases with elevation. The cold front itself remains clearly defined and with a steep slope to a height at least as far as the observations extend. Under these conditions the advancing cold wave remains undiminished in intensity as it advances eastward, usually proving to be more severe instead of less severe than is anticipated in the east. Such cold waves produce at all levels above $\mathrm{I} \mathrm{km}$ the lowest temperatures observed. At the ground, however, the temperature may not drop quite as low as it may go in the more stable $\mathbf{P}_{\mathrm{C}}$ air mass in which conditions favor radiational cooling of the ground stratum without interference by turbulent mixing. The passage of a sharp deep cold front of this type is usually marked by a rather intense cold front squall with precipitation. Moderation of the cold at the ground usually sets in as soon as the usual thermal stratification begins to appear at upper levels in the cold air mass, but not before then. 
A good illustration of this type of cold front is shown in Section A for Feb. 8, 1933 (Plate XVI). In this case the passage of the cold front at Boston was marked by a temperature fall of more than $30^{\circ} \mathrm{F}$ in two hours, and by a squall of hail and snow which lasted about two hours.

The vertical structure of the $\mathbf{P}_{P}$ air masses more nearly resembles that of the relatively homogeneous cold $\mathbf{P}_{\mathrm{C}}$ air masses than that of the markedly stratified $\mathbf{P}_{\mathrm{C}}$ air. Probably the strong outbreaks of fresh $\mathbf{P}_{P}$ air which reach our north Pacific coast from the northwest, and which advance rapidly eastward across the United States had their origin over the northeastern portion of Asia, and have partaken in the circulation around intense deep disturbances in the Aleutian region. Consequently it may be assumed that they originally were Polar air masses of the deep cold continental type which are to be expected in winter only in eastern continental source regions, where the maritime influence is at a minimum. Originally, then, they were nearly identical with our deep cold $\mathbf{P}_{\mathrm{C}}$ air masses from the Hudson Bay region. And their movement from the source region was associated with the deep strong circulation around intense occluding disturbances in the Aleutian area, just as the movement of our coldest $\mathbf{P}_{\mathbf{C}}$ masses across the Atlantic is associated with deep occluding disturbances in the Icelandic region. And like the fresh Polar Atlantic air masses on the west coast of Europe, the fresh Polar Pacific air masses on our west coast are deep, homogeneous, convectively unstable air masses with very low temperatures at high levels. Although the $\mathbf{P}_{P}$ air masses are somewhat modified in their lower layers in crossing the western mountain ranges, the deep strong currents of this type retain to a marked degree even in the central and eastern United States, where they are usually designated as $\mathbf{N}_{\mathbf{P P}}$, their convective instability and pronounced coldness at upper levels. Naturally, after their crossing of the Pacific, they are warmer and moister at all levels than they were in the source region, or than our corresponding deep fresh $\mathbf{P}_{\mathrm{C}}$ air masses in the eastern United States. But they may be markedly colder and drier at the $4 \mathrm{~km}$ and $5 \mathrm{~km}$ levels than the extremely stratified $\mathbf{P}_{\mathrm{C}}$ air masses which are observed so frequently advancing from Alaska and the Canadian northwest. They are, however, much warmer and moister at the ground than the shallow surface cold stratum of the stratified $\mathbf{P}_{\mathrm{C}}$ air masses.

From this brief comparison of the vertical structure of the $\mathbf{P}_{P}$ air masses with that of the stratified and that of the relatively homogeneous $\mathbf{P}_{\mathrm{C}}$ air masses, it is easy to draw conclusions as to the structure of the $\mathbf{P}_{\mathrm{P}}-\mathbf{T}_{\mathrm{M}}$ cold fronts. The air mass contrasts, and presumably also the sharpness of the front, is less pronounced at the ground than in the case of any of the $\mathbf{P}_{C}-\mathbf{T}_{M}$ cold fronts. But at upper levels the air mass contrast and sharpness of the front remain undiminished or even increase somewhat, and the slope of the cold front remains steep, all as in the case of the deep relatively homogeneous $\mathbf{P}_{\mathrm{C}}$ cold fronts. This is found often to be true even in the southwestern United States, where nearly all of the $\mathbf{P}_{C}$ cold wedges are of the shallow stratified type, with overrunning warm currents usually of $\mathbf{T}_{\mathrm{S}}$ air. Probably the very depth of the cold $\mathbf{P}_{\mathrm{P}}$ air mass in this region often acts in part as a barrier to the usual warm dry current aloft, and favors the deepening of the moist convectively unstable $\mathbf{T}_{\mathrm{G}}$ air mass in the warm sector. Hence in spite of the much greater surface air mass contrasts occurring at the $\mathrm{P}_{\mathrm{C}}$ cold front in this region, one would expect greater frontal activity to accompany the passage of a steep $\mathbf{P}_{\mathbf{P}}$ cold front which retains its sharpness and the air mass contrast up to high levels. This same opinion was recently expressed by $\mathrm{H}$. Wexler in the course of a discussion with me 
in which he pointed out that it is commonly accepted as a fact by the Weather Bureau forecasters in Washington that thunderstorms and tornadoes are more likely to occur in the south and west with $\mathbf{P}_{\mathrm{P}}$ cold front passages than with $\mathbf{P}_{\mathrm{C}}$. Doubtless these convective phenomena depend to a large extent not only on the steepness and sharpness of the cold front aloft, but also on the depth of the convectively unstable moist $T_{G}$ air mass ahead of the cold front, by whatever means the deepening of this air mass may be effected.

A typical $P_{P}$ cold front will.be found on cross-section B for Oct. I 5, I 933, and on section A for Oct. I6 and Oct. 17, I933 (Plates XXIV, XXV, and XXVII). However, in this case the $\mathrm{P}_{P}$ cold wedge is observed to become shallower and less intense as it moves southward, more in the manner of the usual $\mathbf{P}_{\mathrm{C}}$ wedge, so that on Section $\mathrm{B}$ for Oct. 16 (Plate XXVI) we find the cold front slope aloft considerably reduced from that of the same section on Oct. I 5 . At the same time the dry $\mathbf{T}_{\mathrm{S}}$ current aloft, which on the previous day appeared at the $5 \mathrm{~km}$ level, has come down to about the $3 \mathrm{~km}$ level. Showers and thunderstorms occurred generally with the passage of this front, except in the far southwest where it became relatively ineffective. The air mass contrasts were somewhat smaller in this case than they would have been in midwinter. Probably the reason why the $\mathbf{P}_{\mathrm{P}}$ cold front became so ineffective in the west Gulf region in this case lies in the fact that the principal air mass advance was eastward rather than southeastward. In winter strong $\mathbf{P}_{\mathbf{P}}$ outbreaks frequently advance directly southeastward from the north Pacific coast to the Gulf of Mexico.

\section{The Structure of the Fronts between $\mathbf{P}_{\mathrm{P}}$ and $\mathbf{P}_{\mathrm{C}}$ Air Masses, and of the Secondary Fronts within $\mathrm{P}_{\mathrm{C}}$ Air Masses}

As a general rule, the fronts between or within cold air masses are dynamically and synoptically of less importance than the fronts between Polar and Tropical air masses. This follows in part from the smaller air mass contrasts at the front, and in part from the fact that such fronts, especially when they are of the occluded type, are likely to be in the process of disintegration. Consequently the study of fronts of these types is likely to be neglected in favor of the more striking phenomena. This helps to explain the fact that there is very little material among the cross-section periods selected for this study from which illustrative cross-sections through occluded and secondary cold fronts may be chosen. However there are certain generalizations about such fronts which may be made with a fair degree of justification, and which seem worth pointing out.

In the first place, it rarely happens that a strong eastward advance of $\mathbf{P}_{P}$ or $\mathbf{N}_{P P}$ air occurs when the deep homogeneous $\mathbf{P}_{\mathrm{C}}$ air predominates in the eastern or central part of the country. This probably follows from the fact that these deep homogeneous outflows of $\mathbf{P}_{\mathrm{C}}$ air occur only in the form of a strong northerly current at all levels. If a $\mathbf{P}_{\mathrm{P}}$ current appears on the north Pacific coast under these conditions, it will also advance southward along the coast, rather than eastward, so that the $\mathbf{P}_{\mathrm{C}}$ air mass may even extend its influence westward towards the coast in the Rocky Mountain region. If these two air masses should lie adjacent along a common front, the $\mathbf{P}_{\mathrm{P}}$ air mass should be notably and uniformly the warmer air mass at all levels.

The rapid eastward advance of the deep cold $\mathbf{P}_{\mathrm{P}}$ or $\mathbf{N}_{\mathrm{PP}}$ air masses can occur only as the prevailing air flow across the United States is from west to east. Under these conditions the $\mathbf{P}_{\mathrm{C}}$ air masses in the eastern and central United States are bound to be of the shallow stratified type moving southeastward from Alaska and the Canadian northwest. 
The eastward sweep of the $\mathbf{P}_{\mathbf{P}}$ air masses usually follows the intense development and occlusion of a disturbance somewhere along the north Pacific coast. Consequently the forward boundary of the $\mathbf{P}_{\mathrm{P}}$ air mass is marked by an occluded front, either of the warm front or the cold front type, depending upon the coldness of the $\mathbf{P}_{\mathrm{C}}$ or $\mathbf{N}_{\mathrm{PC}}$ air mass against which the $\mathbf{P}_{\mathrm{P}}$ current is advancing. Usually the $\mathbf{T}_{\mathrm{P}}$ or $\mathbf{N}_{\mathrm{TP}}$ air at upper levels in the occluded trough gradually disappears as the front advances eastward across the central and eastern United States, but remnants of the high cloud deck are likely to persist. However, such a front gives no precipitation east of the Rockies, unless the northward movement of $\mathbf{N}_{\mathrm{PC}}$ in advance of the front is sufficient to introduce $\mathbf{T}_{\mathrm{G}}$ air from the Gulf into the frontal system. In that case a $T_{G}$ warm sector is bound to be established, and the development of a new disturbance occurs. This leads to the establishment of a $\mathbf{P}_{\mathrm{P}}-\mathbf{T}_{\mathrm{G}}$ cold front of the structure discussed above (p. 29) with the usual occurrence of cold front convective precipitation.

However, in the normal case the $\mathbf{P}_{\mathrm{P}}-\mathbf{N}_{\mathrm{PC}}$ occluded front advances rapidly eastward across the country, without any marked frontal development, yet the frontal discontinuity in the pressure field and the wind shift are likely to remain quite pronounced at all levels. The temperature and moisture discontinuity at the $\mathbf{P}_{\mathrm{P}}-\mathbf{N}_{\mathrm{PC}}$ occluded front is usually quite insignificant at low levels, but with increasing elevation there is normally a pronounced tendency for the $\mathbf{P}_{P}$ air mass to become increasingly cold and dry, i.e., for the occluded front to be an effective cold front at upper levels. This may account for the persistence of occluded fronts of this type in the course of their movement across the entire country.

A fair example of this type of $\mathbf{P}_{\mathbf{P}}-\mathbf{N}_{\mathbf{P C}}$ occluded front appears on the cross-sections $A$ for Dec. 6 and 7, I93I (Plates II and III). In this case the frontal discontinuity is not very sharp aloft, but the maximum temperature difference, as shown by the soundings at Omaha and Cleveland on the 6 th, occurs at about the $5 \mathrm{~km}$ level. A secondary maximum temperature difference between Chicago and Cleveland occurs just above $\mathrm{I} \mathrm{km}$, apparently a result of the establishment by the fresh winds just behind the occluded front of a homogeneous layer at Chicago slightly more than $\mathrm{I} \mathrm{km}$ in depth. On the following day the current low temperature at Omaha at the $5 \mathrm{~km}$ level has been displaced to Boston.

It frequently happens that the eastward advance of the deep $\mathbf{P}_{\mathrm{P}}$ current across the United States is accompanied by a similar but more southeastward moving mass of $\mathbf{P}_{\mathrm{C}}$ air from the Canadian northwest. The shallow cold $\mathbf{P}_{\mathrm{C}}$ air mass tends under these conditions to underrun the $\mathbf{P}_{\mathrm{P}}$ air current along its northern edge as a shallow cold wedge, and gradually to displace more and more of the $\mathbf{P}_{P}$ air mass at the ground. Such a development may be said even to be a normal feature of our major eastward advances of $\mathbf{P}_{P}$ air during the winter. This occurrence is so frequent, and the synoptic sequence so uniformly characteristic, that it should be briefly described. Upon the first appearance of the shallow cold $\mathbf{P}_{C}$ wedge in the northwest, the surface air mass contrast $\left(\mathbf{P}_{\mathrm{P}}-\mathbf{P}_{\mathrm{C}}\right)$ is very pronounced. The $\mathbf{P}_{C}$ cold front at the ground is sharply marked by a trough in the isobars, wind shift, and temperature discontinuity. Presumably, however, this sharp front becomes nearly horizontal and rather diffuse within 2 or $2 \frac{1}{2} \mathrm{~km}$ above the ground. But there are initially two well-marked and distinct anticyclones centered in the two Polar air masses. With the eastward advance of this system, however, there invariably occurs a rapid disintegration of the surface $\mathbf{P}_{\mathrm{P}}-\mathbf{P}_{\mathrm{C}}$ front. The pressure trough fills, anticyclogenesis accompanied by $\mathrm{a}$ merging of the two separate centers occurs, the wind and temperature discontinuity disappear, and a relative surface warming up within the $\mathbf{P}_{\mathrm{C}}$ air mass and surface cooling 
within the $\mathbf{P}_{P}$ mass take place. This sequence suggests that active subsidence is taking place aloft in the deep cold $\mathbf{P}_{\mathrm{P}}$ air mass.

A typical example of a sequence of this type is shown on the synoptic charts for Dec. 7 and 8, 193I, and on the cross-sections A for these two days (Plate II ff.). In this case active anticyclogenesis was accompanied by marked horizontal divergence and subsidence in most of the $P_{P}$ air mass at the same time that it was being displaced at the ground by the $\mathbf{P}_{\mathrm{C}}$ wedge. The rapid displacement of Polar air at high levels by the advance of a current of Tropical maritime origin was occurring simultaneously.

Probably the commonest case of front formation between two $\mathbf{P}_{\mathrm{C}}$ air masses is that which follows the occlusion of an active disturbance with an open warm sector. In the case of such an active occlusion, the occluded front will normally be an effective cold front at all levels, as fresh $\mathbf{P}_{\mathbf{C}}$ air advances against old returning $\mathbf{N}_{\text {PC }}$. The occluded center usually moves rather slowly, and the occluded front swings slowly around it as the trough gradually fills and the frontal discontinuity weakens. Such occluded fronts possess little synoptic or dynamic significance in themselves, except for the fact that the base of the occlusion, where the open warm sector terminates, is a point at which the development of a secondary disturbance is likely to occur. This is especially true of the $\mathbf{P}_{\mathrm{C}}-\mathbf{N}_{\mathrm{PC}}$ occluded fronts which reach the middle or south Atlantic coast, where there is usually an abundance of $\mathbf{T}_{A}$ air available for the embryo warm sector. Unfortunately it has been impossible as yet to obtain the data for a cross-section through such an actively developing secondary disturbance.

In the case of slowly moving deep occluded disturbances there is a phenomenon frequently observed which occurs coincidentally with the gradual weakening of the $\mathbf{P}_{\mathrm{C}}-\mathbf{N}_{\mathbf{P C}}$ occluded front within the occluded disturbance. This consists in the gradual development at the ground of a pressure trough and wind discontinuity within the fresh $\mathbf{P}_{\mathrm{C}}$ current in the opposite direction from the center of the disturbance to that in which the occluded front extends. This implies a certain degree of horizontal convergence and slow frontogenesis within the non-homogeneous $\mathbf{P}_{\mathrm{C}}$ current. The tendency in the analysis of the surface map is always to extend the occluded front in the opposite direction into such a frontogenetic zone, but it is generally recognized now that this surface formation cannot be explained either dynamically or hydrostatically by conditions in the lower troposphere. Frequently quite definite secondary cold fronts are formed in this way, especially in spring when the movement of the deep occluding disturbances is especially slow, and the fresh $\mathbf{P}_{\mathbf{C}}$ currents are particularly' non-homogeneous, latitudinally. Widespread convective precipitation may occur with such secondary cold fronts. Observations showing marked coldness aloft and instability to high levels within the $\mathbf{P}_{\mathrm{C}}$ current prove the convective nature of the precipitation, and the impossibility of explaining the frontogenesis in terms either of an upper warm current from the occluding trough of the disturbance or of adiabatic heating of the forward portion of the $\mathbf{P}_{\mathrm{C}}$ current. Furthermore, we must note that the movement of such a secondary cold front is quite independent of (usually much less than) the component of the gradient wind normal to the front, and that occasionally with deep stationary disturbances we observe a series of such weak secondary cold fronts which develop in a manner such that the front disappears in a more advanced position and reappears in a more retarded position. These facts indicate-strongly that the genesis of such secondary cold fronts is a reflection of intense dynamic activity in the upper troposphere, and is probably associated with the usual retrograde displacement above the $\mathbf{P}_{\mathrm{C}}$ current of the center of the occluded disturbance, and with an accompanying low 
tropopause. Palmén's ${ }^{1}$ work with sounding balloon observations in northern Europe has furnished convincing observational evidence favoring such an explanation of similar pressure-trough formation and frontogenesis within a cold deep Polar air outflow following the occlusion of an intense disturbance. Refsdal, ${ }^{2}$ on the other hand, explains such cyclogenesis and frontogenesis within the cold Polar current much less convincingly in terms of the "Feuchtlabilität," or convective instability of the cold air mass. Unfortunately, lack of data prevented the inclusion of a cross-section through this type of secondary cold front. However, the outstanding characteristic of such a cross-section would doubtless be the coldness of the $\mathbf{P}_{\mathrm{C}}$ air mass aloft, in contrast to those cases of surface frontogenesis within a shallow $\mathbf{P}_{\mathrm{C}}$ stratum effected by overrunning warm currents of Pacific or Gulf origin (See p. 24 ff.).

This concludes the general discussion of questions raised by the analysis of crosssections. Much more information of value to dynamic and synoptic meteorology will doubtless be obtained by an extension of the cross-section method of synoptic representation. The vertical extension of the cross-sections through the tropopause is an important improvement which can be made part of the routine practice only when we have regular daily ascents by radio sounding balloons. Another very important extension of the method will follow the establishment of any observational technique which makes possible regular soundings under all atmospheric conditions. It will be noted that not a single cross-section discussed in this paper passes through an actively developing frontal disturbance. This is owing to the failure of the aeroplane observations under such conditions. Hence probably the most important problem in synoptic meteorology has been entirely omitted from the present discussion.

${ }^{1}$ E. Palmén, Registrierballonaufstiege in einertiefen Zyklone, Mitteilungen des Meteorologischen Instituts der Universität Helsingfors, no. 26,1935 .

2 A. Refsdal, Zur Thermodynamik der Atmosphäre, Geofysiske Publikationer, vol. IX, no. I2, Oslo, I932. 


\section{NOTES ON FEATURES OF INTEREST ON THE INDIVIDUAL CROSS-SECTIONS}

In the following discussion of the individual cross-sections for the periods chosen for illustration in this paper, no attempt will be made to describe in detail, or to interpret, the general meteorological activity taking place. It will be assumed that the general features of the meteorological sequence in each period are made sufficiently clear by the 8 A.M. synoptic chart which is reproduced for each day for which cross-sections are presented. Only scattered comments on noteworthy features of the individual cross-sections will be offered. The presentation of the maps and cross-sections at the back of this paper is arranged so that the different periods appear in chronological sequence. For each period the presentation is also chronological so that the A.M. synoptic chart for each day is immediately followed by the cross-sections $\mathrm{A}, \mathrm{B}$, and $\mathrm{C}$ for the same morning, or by those of the sections for which there are satisfactory data.

\section{A. First Period (Dec. 6-8, i93i. Plates I-VI)}

Dec. 6. Section A: We find on this section a rather typical occluded front between $\mathbf{N}_{P P}$ and $\mathbf{N}_{\text {PC }}$ air, with the normal increase of the air mass contrast at upper levels, between Cleveland and Omaha. In this case, however, there is a marked prefrontal cooling at upper levels at Chicago which decreases the sharpness of the front appreciably. The turbulent production of a homogeneous layer just behind the front increases the frontal discontinuity near the $I \mathrm{~km}$ level. Scattered showers occurred in the unstable $\mathbf{N}_{P P}$ air mass in the Lake region just behind the front.

Section B: This section shows a typical $\mathbf{N}_{\mathrm{PP}}-\mathbf{T}_{\mathrm{G}}$ cold front, with the usual dry $\mathbf{T}_{\mathrm{S}}$ stratum above the $\mathbf{T}_{\mathrm{G}}$. The $\mathbf{T}_{\mathrm{S}}-\mathbf{T}_{\mathrm{G}}$ front is indicated as a warm front, as usual, for it is assumed that the $\mathbf{T}_{\mathrm{S}}$ current is descending along the front of the cold wedge, and it is doubtless slightly warmer than the $\mathbf{T}_{G}$ at the $2 \mathrm{~km}$ level. The principal contrast however, is that of the moisture, which is shown by the crowding of the specific humidity isopleths along the $\mathbf{T}_{\mathrm{S}}-\mathbf{T}_{\mathrm{G}}$ front. Above about $3 \frac{1}{2} \mathrm{~km}$ the $\mathbf{T}_{\mathrm{S}}$ air mass is found to have the steep lapse rate which so frequently characterizes it at high levels.

Dec.7, Section A: On this section we find the same deep cold $\mathbf{N}_{P P}$ at Boston which was observed at Omaha on the previous day. Meanwhile the rapid advance of a warmer and moister current has taken place at high levels in the middle west, with the typical very diffuse upper warm front. However, the moisture increase at Cleveland and Chicago from the $2 \frac{1}{2}$ to the $4 \mathrm{~km}$ level, in spite of the temperature decrease, proves conclusively that the rise in temperature from that of the previous day is caused by the advance of a warmer air mass rather than by subsidence within the $\mathbf{N}_{P P}$ mass.

Section B: We note on this section the shallowness of the extensive Polar air masses in the west, both the $\mathbf{N}_{P P}$ and the fresh $\mathbf{P}_{C}$ wedge. The section represented is typical in that the overrunning air above the Polar masses is fairly homogeneous $\mathbf{N}_{\text {TP }}$ except near the Gulf region, where $T_{G}$ appears at high levels. The shallowness of the fresh $\mathbf{P}_{\mathrm{C}}$ air observed here is characteristic of such $\mathbf{P}_{\mathrm{C}}$ wedges which underrun extensive air flows from the Pacific. 
Section $\mathrm{C}:$ In this southern section the most outstanding feature is the broad trough of horizontally homogeneous warm moist $\mathbf{T}_{G}$ air aloft. Horizontal homogeneity is likely to be more characteristic of this air mass than of any other. The warm dry air found aloft at Norfolk on this section may quite possibly be subsiding $\mathbf{N}_{P P}$ instead of $\mathbf{T}_{\mathrm{s}}$, for it is probably dry enough to permit of such an explanation, and it is slightly cool for $\mathbf{T}_{\mathrm{s}}$ air. Such an interpretation would extend the $\mathbf{N}_{P P}$ air mass to the upper of the two fronts and would make the lower front a subsidence inversion in this region.

Dec. 8, Section A: We have here a sequence of five ascents at Boston which show the rapid lowering during the day of a warm stratum aloft. Unfortunately, all except the first one have no humidity measurement, and do not extend to quite the elevation that would be desirable. It is assumed that the warm air coming in aloft belongs to the $\mathbf{N}_{\text {TP }}$ current noted on the same section in the middle west on the preceding day. It is to be noted, however, that this current in the middle west (Chicago) has become warmer and drier since the preceding day. Therefore it is now designated as $\mathbf{T}_{\mathrm{g}}$ instead of $\mathbf{N}_{\mathrm{TP}}$. Such moisture changes are frequently observed in these upper warm currents, and they are probably best explained in this manner. It is also to be noted how outstanding the first appearance of the $T_{G}$ current from the southwest is at Omaha. The influence of this current was just noted at Chicago at the $5 \frac{1}{2} \mathrm{~km}$ level, with cirro stratus clouds moving from the west above that level.

Section B: This abbreviated section shows very clearly at Omaha a typical intermediate stratum of dry $\mathbf{T}_{\mathrm{S}}$ air, with the uniformly warm moist $\mathbf{T}_{\mathrm{G}}$ above, and the shallow $\mathbf{N}_{\mathbf{P P}}$ stratum at the ground. The moist southerly $\mathbf{T}_{G}$ current has completely displaced the $\mathbf{T}_{\mathbf{S}}$ stratum at Dallas, and extends at least to the top of the sounding.

Section C: On this section the very stations which are needed to show the structure of the warm current aloft in the warm front rain zone, Pensacola and Due West, are missing, as is usual in such cases. Consequently the representation of the warm sector presented here is quite hypothetical. It is interesting to note the pronounced lack of horizontal homogeneity within the $\mathbf{P}_{\mathrm{C}}$ air mass shown to exist between Due West and Boston. Such lack of horizontal homogeneity is typical of the shallow outbreaks of stratified $\mathbf{P}_{\mathrm{C}}$ air, such as the present one.

\section{B. Second Period (Jan. I2-I6, I932. Plates VI-XV)}

Jan. I2, Section A: This section shows very well the type of gradual transition from the Polar to the Tropical air masses which is so typical of the broad northward movement of air behind an extensive stagnant Atlantic coast anticyclone. We find the gradual transition from returning $\mathbf{N}_{P C}$ through the moister and slightly warmer northern portion of the modified $\mathbf{T}_{\mathrm{G}}$ current, to the warm dry $\mathbf{T}_{\mathrm{S}}$ aloft in the middle west. A shallow layer of $\mathbf{N}_{P C}$ remains at the ground in this northern section. The $\mathbf{T}_{G}$ warm front at the surface is still far to the south, so that its slope must be very slight, a fact which accounts for the light and widely scattered nature of the warm front rain.

Section B: This abbreviated section shows the typical stratification in temperature and moisture of horizontally homogeneous $\mathbf{T}_{\mathrm{S}}$ above shallow $\mathbf{N}_{\mathrm{PP}}$. It is worthy of note that in this case the $\mathbf{T}_{\mathbf{S}}$ is slightly warmer and drier at Omaha in the north than at Dallas in the south. This is the reverse of the usual condition.

Section C: Except for the $\mathbf{P}_{C}$ and $\mathbf{N}_{P C}$ in the northeast, this southern section lies mostly in the tropical air masses. Notable is the trough of $\mathbf{T}_{A}$ air along the middle Atlantic coast (Norfolk, Anacostia) which is markedly moister, though only slightly warmer 
than the $\mathbf{N}_{\mathrm{PC}}$. It is markedly cooler and less moist than the $\mathbf{T}_{\mathrm{G}}$ at Pensacola. It probably represents old $\mathbf{N}_{\text {PC }}$ whose properties have been recently transformed to $\mathbf{T}_{\mathrm{A}}$ over the Gulf Stream. But most noteworthy on this section is the apparent overrunning of the warm moist $\mathbf{T}_{G}$ mass in the southwest by the dry and slightly cooler $\mathbf{T}_{\mathrm{S}}$ current aloft. This unusual occurrence led in this case to the development of heavy thunderstorms along the $\mathbf{N}_{\mathrm{P} \text { P }}$ front. It is impossible from the data here to judge just how far the cooler $\mathbf{T}_{\mathrm{S}}$ air mass advanced aloft. It is possible that the $\mathbf{T}_{\mathrm{S}}-\mathbf{T}_{\mathrm{G}}$ front is much more nearly vertical than represented.

Fan. ${ }_{3}$, Section $\mathrm{A}$ : We find on this section in the east a rather questionable $\mathbf{N}_{\mathrm{TP}}-\mathbf{T}_{\mathrm{G}}$ stratification. The $\mathbf{N}_{\mathrm{TP}}$ has nearly the same temperature as the $\mathbf{T}_{\mathrm{G}}$, but it is definitely slightly drier at all levels, and has brought with it in the middle west a distinct decrease in moisture from the $\mathbf{T}_{\mathrm{G}}$ values of the day before. The appearance given by the isotherms as drawn through the Boston ascent that the $\mathbf{N}_{\mathrm{TP}}$ is level for level colder than the $\mathbf{T}_{\mathrm{G}}$ is not correct. A careful drawing of these isotherms should show a small inversion at the $\mathbf{N}_{\mathrm{TP}}$ warm front at Boston. In the middle west the usual warmth and dryness of the $\mathbf{T}_{\mathrm{S}}$ aloft relative to the $\mathbf{N}_{\mathrm{TP}}$ below stand out very clearly. At Omaha we find the ideal type of $\mathbf{P}_{\mathrm{C}}$ cold front structure.

Section B: On this section we note the extreme stratification of the northwestern $\mathbf{P}_{\mathrm{C}}$ cold wedge. The moisture distribution permits of a subsidence explanation of the inversion appearing at Ellendale on this day, as is suggested in the analysis of the crosssection. However, by the following day we have to invoke the aid of active advection in order to explain the rapid changes which occur in the upper levels of this wedge of cold air. We note on this section again the characteristic extreme warmth of the $\mathbf{T}_{\mathrm{S}}$ air mass at intermediate levels, and steep lapse rate aloft.

Section C: This southern section is rather unique for a winter cross-section in that only Tropical air masses appear on it. The frontal surfaces are naturally rather diffuse, the atmosphere as a whole showing remarkable thermal homogeneity from New England to Texas. The air mass differences show up much more clearly in the moisture distribution. But even in this element there appear no abrupt transitions, owing to the fact that the intermediate $\mathbf{N}_{\mathrm{TP}}$ mass serves as a broad transition zone between the moist $\mathbf{T}_{\mathrm{G}}$ in the east and the dry $T_{S}$ aloft in the southwest.

fan. I4, Section A: The eastern portion of this section retains practically the same structure which existed on the preceding day, a moderate stratification of tropical air masses with $\mathbf{T}_{\mathrm{S}}$ overrunning $\mathbf{N}_{\mathrm{TP}}$. The cold front in the west has advanced very slowly. The cold wedge at Omaha shows the same extreme thermal stratification which was observed at Ellendale on the preceding day. But in this case the warm air aloft is saturated with a moisture content exceeding $4 \mathrm{~g}$ at intermediate levels. This completely eliminates the possibility of any subsidence explanation of the thermal stratification, and suggests the presence of an $\mathbf{N}_{\mathrm{TM}}$ air mass above the shallow $\mathbf{P}_{\mathrm{C}}$. As this moist current is much too cold to be a part of the $\mathbf{T}_{\mathrm{G}}$ current moving northward from the Gulf, and as it is a westerly current, it is assumed to be $\mathbf{N}_{\mathrm{TP}}$ from rather far north in the Pacific. The surface map indicates the possibility of such a trajectory of the upper current in this case. This $\mathbf{N}_{\mathrm{TP}}$ is definitely colder than the $\mathbf{T}_{\mathrm{S}}$ at the same level at Chicago, so its presence aloft extends the depth of the effective cold wedge.

Section B: Here we find the typical southern cold front structure, with extreme $T_{G}-$ $\mathbf{T}_{\mathrm{S}}$ stratification at Dallas in the warm sector, just in advance of the cold front. On this section again the shallowness of the very cold $\mathbf{P}_{\mathrm{C}}$ stratum is striking. But there is a great 
contrast in moisture and a rather large difference in temperature between Ellendale and Omaha in the westerly current aloft. We have already decided to designate the upper air mass at Omaha as $\mathbf{N}_{\mathrm{TP}}$, but since we observe strong west or westsouthwest winds aloft at Ellendale it seems probable that the upper current there too is of Pacific origin. It must necessarily come from the Polar Pacific source region, to judge from its properties. Thus we have in this case above the shallow $\mathbf{P}_{\mathrm{C}}$ wedge an upper front between Polar and Tropical Pacific air masses.

Section C: On this section again, as on the preceding day, only Tropical air masses occur. This is a fine instance of a broad, foggy and cloudy $T_{G}$ current, giving way at quite low levels to the warm dry $\mathbf{T}_{\mathrm{S}}$ air mass aloft. General horizontal homogeneity prevails throughout each of the Tropical air masses. Above the usual marked stratification associated with the transition from the $T_{M}$ to the $T_{S}$ air masses, we note the normal steep lapse rate at upper levels in the $\mathbf{T}_{\mathrm{S}}$ current. The $\mathbf{T}_{\mathrm{G}}-\mathbf{T}_{\mathrm{S}}$ front is indicated as a cold front on this section because it is believed that the cooler $\mathbf{T}_{\mathrm{G}}$ stratum is deepening.

Fan. 15, Section A: The principal change in this section since the previous day is the appearance of the well defined $T_{G}$ warm sector, narrow at the ground and spreading out aloft. The $\mathbf{T}_{\mathrm{G}}$ current has displaced the $\boldsymbol{T}_{\mathrm{S}}$ to well above the $4 \mathrm{~km}$ level just in advance of the cold wedge, which is advancing very slowly. At Cleveland, where the $\mathbf{T}_{G}$ is deepest, we find a thunderstorm in progress. One noteworthy feature is the fact that in this narrow northern portion of the $T_{G}$ warm sector the vertical extent of the $T_{G}$ air mass is double its depth along the Gulf coast in the south where its horizontal extent is much greater. This is quite typical of $\mathbf{T}_{\mathrm{G}}$ warm sectors, and implies considerable horizontal convergence in the northward moving $\mathbf{T}_{\mathrm{G}}$ current. The slowly advancing cold wedge has undergone another change, in that the warm moist air aloft in the forward portion of the wedge (Omaha) on the preceding day has been displaced completely by the much drier and slightly cooler $\mathbf{N}_{P P}$ which was found at Ellendale on the day before.

Section $B$ : On this section we find the $T_{G}-T_{S}$ stratification ahead of the cold front almost unchanged from the previous day. The front itself has advanced only slightly, and appears to be approaching a stationary condition. The cold wedge, as noted on section $A$, has now become uniformly dry above the shallow $\mathbf{P}_{\mathrm{C}}$ layer, which is interpreted as being the result of the displacement of $\mathbf{N}_{\mathrm{TP}}$ by $\mathbf{N}_{\mathrm{PP}}$. However, the slope of the isotherms in this $\mathbf{N}_{P P}$ air mass aloft indicates a marked degree of thermal non-homogeneity.

Section C: This section remains almost the same as on the previous day, the condition being essentially that of pronounced $\mathbf{T}_{G}-\mathbf{T}_{\mathrm{S}}$ stratification, with marked horizontal homogeneity. The only changes from the same section of the preceding day are found in the advance and deepening of the $T_{G}$ current towards the northeast, and in the appearance of the $\mathbf{P}_{C}$ wedge to a depth of $\mathrm{I} \mathrm{km}$ at Dallas at the western extremity of the section.

Fan. 16 , Section A: We note on this section that the advancing cold wedge has retained its stratified structure of the previous days, but the surface $\mathbf{P}_{\mathrm{C}}$ stratum has been so greatly modified that the stratification in the east is much less pronounced than during its earlier life history. The difference between the morning and the afternoon soundings at Boston in the moisture content of the upper strata of the cold wedge suggests that there may still be present a little of the $\mathbf{N}_{\mathrm{TP}}$ air observed two days previously at Omaha in the upper foremost portion of the cold wedge. The influence of the $\mathbf{T}_{G}$ current advancing northward from the Gulf is clearly shown at Chicago and Omaha at about the $3 \frac{\mathrm{T}}{2} \mathrm{~km}$ level. 
Section B: On this section the pronounced $\mathbf{P}_{\mathrm{C}}-\mathbf{N}_{\mathbf{P} \mathbf{P}}$ stratification in the stationary cold wedge remains almost unchanged from the day before. But a great change has taken place at upper levels, where we find that moist $\mathbf{T}_{\mathrm{G}}$ is actively displacing the warm dry $\mathbf{T}_{\mathrm{S}}$ current of the previous day above the cold wedge. In other words, the stationary cold front has suddenly been transformed to an active warm front, with the appearance of a broad warm front precipitation area.

Section C: Along the middle Gulf coast this southern section still shows the marked stratification present during the past two days in the shallow moist $\mathbf{T}_{G}$ stratum with warm dry $\mathbf{T}_{\mathrm{s}}$ air just above. In the northeast, however, the Tropical air masses have been displaced by the stratified $\mathbf{N}_{P G}-\mathbf{N}_{P P}$ cold wedge discussed in section $A$. In the west we note the tremendous deepening of the $\mathbf{T}_{\mathrm{G}}$ air above the stationary $\mathbf{N}_{\mathrm{PC}}$ cold wedge in the course of the development of active warm front conditions, as shown on section $\mathrm{B}$. The frontal structure in this case, with the deepening of the $T_{G}$ air above the former cold front, is characteristic of this type of transformation.

\section{Third Period (Feb. 8-io, 1933. Plates XVI-XXI)}

Feb. 8, Section A: On this section we find a cold front at which the air mass contrast and the sharpness of the front are about as extreme as are likely to be met with. It is typical of a cross-section through the transition zone between a $\mathbf{P}_{\mathrm{C}}$ air mass of the coldest most homogeneous type, and a normal stratified warm sector with $\mathbf{T}_{\mathrm{S}}$ above $\mathbf{T}_{\mathrm{G}}$. There is a shallow wedge of $\mathbf{N}_{P P}$ indicated just ahead of the cold front, whose presence was justified by the preceding maps as well as by the current data, but which probably played a negligible role in the dynamics of the frontal structure. The passage of this steep sharp front was accompanied by a heavy squall of sleet and snow, and a termperature drop of $30^{\circ} \mathrm{F}$ in two hours. On the summit of Mt. Washington, at the $2 \mathrm{~km}$ level, the front passage occurred at about the same time as at Boston, and was followed by a drop of temperature of $55^{\circ} \mathrm{F}$ in ten hours. We note also a shallow secondary cold front in the far west which appears to be quite pronounced near the ground, but which like most fronts of its kind may be expected to disintegrate as it advances eastward.

Section C: This section shows the structure of the cold front in the south to be essentially the same as in the north. The smaller slope of the front on this section may be explained by the fact that it is cut much less nearly at right angles than in section $A$. The presence of the narrow $\mathbf{P}_{\mathrm{P}}$ sector is clearly indicated by the ascent at Atlanta, on which both frontal surfaces stand out quite unmistakably. The structure of the Tropical air masses in the warm sector is little different from that on the northern section, but it will be noted that the cold $\mathbf{P}_{\mathrm{C}}$ air mass is much more stratified thermally than it is in the north. This rapid stabilization is characteristic of all of the deep initially homogeneous $P_{C}$ air masses in the course of their southward progress across the United States. It is probably mostly the effect of subsidence at upper levels.

Feb. 9, Section A: There has been no change of importance on this section since the preceding day. The cold front has advanced steadily eastward, but it seems to be lessening in steepness and intensity aloft, to judge by the large temperature inversion and backing of the wind to southwest at Boston between 4 and $4 \frac{1}{2} \mathrm{~km}$. The shallow cold wedge has advanced in the west, but with a weakening of its identifying characteristics. Also in the west the stabilizing process, probably subsidence, is making steady progress at upper levels.

Section B: This section brings out well the usual non-homogeneity of the $\mathbf{P}_{C}$ wedge in the north-south direction, and also the usual shallowness of the $\mathbf{P}_{\mathrm{C}}$ wedge in the south. 
In this case the overrunning air current, which is moderately cold and moist, seems to be transitional Polar Pacific air from the west.

Section C: This section shows clearly the shallowness of the whole southern lobe of the extensive $\mathbf{P}_{\mathrm{C}}$ air mass, which deepens somewhat in the northeast towards Boston. The upper air mass at Atlanta is markedly warmer and moister than the westerly current of $\mathbf{N}_{\mathrm{PP}}$ air at Dallas. In fact, it is slightly warmer and moister than the $\mathbf{T}_{\mathrm{G}}$ at the same level on the previous day, a fact which forces one to conclude that there is still $\mathbf{T}_{\mathrm{G}}$ in this region above the $3 \mathrm{~km}$ level. This would scarcely have been suspected from the surface map.

Feb. IO, Section A: On this section again we note only minor changes since the previous day. At Boston the cold air now extends beyond the $5 \mathrm{~km}$ level, in contrast to the day before. In general the extreme cold has been moderating along the whole section, but more rapidly aloft, so that an extensive subsidence inversion is forming, which is the normal development to expect. The shallow secondary cold wedge has entirely lost its identity, as expected.

Section B: This section also shows the moderating tendency in the cold air at all levels, and the tendency toward the formation of a subsidence inversion. The horizontal non-homogeneity of the cold air mass in the south remains as previously. The secondary cold front is still indicated on this section, but is almost non-existent as a discontinuity surface. The $\mathbf{N}_{\text {PP }}$ current aloft seems to be coming lower, and advancing northward as a warm front, but to judge from the Dallas ascent, the precipitation over Texas is falling entirely from a low stratus cloud within the shallow $\mathbf{N}_{\mathrm{PC}}$ air mass.

Section $C$ : This section indicates that in the east the $\mathbf{P}_{C}$ air mass has deepened since the previous day, but in the west it has become shallower, as the $\mathbf{N}_{P P}$ current above has lowered. But the $\mathbf{T}_{G}$ air which was found aloft at Atlanta on the previous two days has entirely disappeared. Its place has been taken by the cooler and drier $\mathbf{N}_{\text {PP }}$. In the east we find the same subsidence inversion which appears on sections $A$ and $B$, but in the west this surface has lowered almost to the ground.

\section{Fourth Period (Ост. I4-I7, I933. Plates XXI-XXVIII)}

Oct. 14, Section A: On this section we find in the $P_{C}$ air mass in the east a typical high level subsidence inversion. The required moisture decrease above the inversion occurs, but the discontinuity in this element would doubtless be much sharper if the observed values were corrected for the sluggishness of the hair hygrometer. In the west we note a typical advance of stratified Tropical air above the subsiding $\mathbf{P}_{\mathrm{C}}$ air mass. A shallow surface southerly current of moist $\mathbf{N}_{\mathrm{TP}}$ at Omaha is observed at Cleveland as a moist northwesterly current with alto stratus clouds above the dry subsiding $\mathbf{P}_{\mathrm{C}}$ air mass. The usual markedly warm and dry $\mathbf{T}_{\mathrm{S}}$ air current occurs at Omaha above the shallow $\mathbf{N}_{\mathrm{TP}}$ stratum.

Section B: This north-south section shows an almost ideal arrangement of the principal Tropical air masses. We find the $\mathbf{N}_{\mathrm{TP}}$ air mass markedly moister than the $\mathbf{T}_{\mathrm{S}}$ mass, but acting as a cold air mass with respect to it at all levels. The $T_{G}$ air mass, on the other hand, is markedly moister and warmer than the $\mathbf{N}_{\mathrm{TP}}$ at all levels, but below the $\mathrm{I} \frac{1}{2} \mathrm{~km}$ level is nevertheless colder than the $\mathbf{T}_{\mathrm{S}}$ air mass. Above this point it becomes level for level gradually warmer than the $\mathbf{T}_{\mathrm{S}}$. As a result, the $\mathbf{T}_{G}-\mathbf{T}_{\mathrm{S}}$ front is in the nature of a cold front up to $I \frac{1}{2} \mathrm{~km}$, and becomes a warm front above that level. It is to be noticed on section, as is usual on sections on which only tropical air masses appear, how much more clearly the air mass contrasts are shown by the isopleths of specific humidity than by those of temperature. 
Section $C$ : On this section we find again clearly marked in the northeast the typical high-level $\mathbf{P}_{\mathrm{C}}$ subsidence inversion noted on section $A$. In the southwest we have a normal $\mathbf{T}_{\mathrm{G}}-\mathbf{N}_{\mathrm{PC}}$ warm front, where the $\mathbf{N}_{\mathrm{PC}}$ has been modified to such an extent that the air mass contrast is small and the front quite diffuse. We note at Dallas again the pronounced protrusion of a dry $\mathbf{T}_{\mathrm{S}}$ stratum into the moist $\mathbf{T}_{\mathrm{G}}$ at low levels where the $\mathbf{T}_{\mathrm{S}}$ is the warmer and consequently the overrunning air mass.

Oct. I5, Section A: The principal change on this section since the previous day is found in the northward advance of the $T_{G}$ current at all levels in the west, as shown by the sounding at Omaha. The position of the $\mathbf{T}_{\mathrm{G}}-\mathbf{T}_{\mathrm{S}}$ front at upper levels is quite uncertain, for no sounding penetrates it, and the temperature contrast of the two air masses is very slight. It was assumed in the analysis of this section that the $\mathbf{T}_{G}$ should probably overrun the $\mathbf{T}_{\mathrm{S}}$ at upper levels in this case, although on the same section two days later at Boston the slope of the $T_{G}-T_{S}$ front is found to be in the opposite direction. In the east we still find the mcdified $\mathbf{P}_{\mathrm{C}}$ air mass at the ground, but the marked increase in moisture as well as in temperature at upper levels since the preceding day establishes the fact that air mass advection rather than continued subsidence is producing these changes aloft. The air mass aloft must be a mixture of $\mathbf{T}_{\mathrm{S}}$ and $\mathrm{N}_{\mathrm{T}}$, for the moisture content is intermediate between the normal values for these two air masses, and the $\mathbf{N}_{T P}$ stratum of the previous day can no longer be identified. The mixing of $\mathbf{T}_{\mathrm{S}}$ with the $\mathbf{T}_{\mathrm{M}}$ air masses occurs quite frequently, especially in summer.

Section B: At the northern end of this section we find an ideal $\mathbf{P}_{\mathrm{P}}-\mathbf{T}_{\mathrm{G}}$ cold front, at which the air mass contrast remains sharply marked to the top of the soundings. The lowlevel stratification of the deep $\mathbf{T}_{G}$ air mass is interesting, for we find clearly marked at Dallas the remnants of $\mathbf{T}_{\mathrm{s}}$ stratification of the previous day. This stratification is to be seen, though not so clearly, even at Omaha, in spite of the fact that the steady northward advance of the $\mathbf{T}_{G}$ current has been displacing $\mathbf{T}_{S}$ aloft and what was apparently $\mathbf{N}_{T P}$ at the surface since the preceding day. Presumably this dry stratum containing an admixture of $\mathbf{T}_{\mathrm{S}}$ air would disappear completely in a north-south section located a short distance to the east of this one, and would be more clearly marked in such a section a short distance to the west.

Oct. I6, Secticn A: On this section we still observe the shallow much modified $\mathbf{N}_{\mathrm{PC}}$ air mass in the east, ar: $d$ above this the $T_{S}$ current with evident $\mathbf{N}_{T P}$ influence near Boston. The sharply marked $\mathbf{P}_{\mathrm{P}}$ cold front has now passed Omaha in the west, but the structure of the $\mathbf{T}_{\mathrm{G}}-\mathbf{T}_{\mathrm{S}}$ front in the warm sector still remains quite hypothetical in the absence of soundings frcm Chicago. The structure represented here, typical of cold fronts accompanied by prefrontal deepening of the moist $\mathbf{T}_{\mathrm{G}}$ air in the absence of a descending $\mathbf{T}_{\mathrm{S}}$ current atove the cold wedge, was chosen to agree with the structure shown by the same front at Boston on the following day.

Section B: On this section we note that as the southward advance of the $\mathbf{P}_{\mathbf{P}}$ wedge beccmes slower, the slope of the cold front is lessening and the cold air mass is rapidly losing its horizontal homogeneity, as usual, in the south. The Tropical air mass in advance of the weakening cold wedge is becoming more stratified with the lowering of the $\mathbf{T}_{\mathrm{S}}$ current along the upper cold front. Simultaneously the $\mathbf{T}_{\mathrm{G}}$ air mass just in advance of the cold front on the previous day has been replaced by a drier $\mathbf{N}_{\mathrm{TP}}$ current from the west.

Section C: On this southern section the outstanding feature is the shallowness of the Tropical maritime air masses in the south, as is so frequently observed to be the case. The $\mathbf{T}_{\mathrm{A}}$ mass (old $\mathbf{N}_{P C}$ ) in the southeast is found notably drier than the $\mathbf{T}_{G}$ along the Gulf coast, in spite of the small temperature differences. Although the temperature differences 
are nearly zero, the $\mathbf{N}_{\mathrm{TP}}$ sector at Dallas is shown to be markedly drier than the shallow $\mathbf{T}_{\mathrm{G}}$ air to the east at the surface, but markedly moister than the $\mathbf{T}_{\mathrm{S}}$ on either side at upper levels. On this section again, the $\mathbf{T}_{\mathrm{S}}, \mathbf{N}_{\mathrm{TP}}, \mathbf{T}_{\mathrm{G}}$, and $\mathbf{T}_{\mathrm{A}}$ air masses are characterized by completely negligible temperature differences, level for level, but by pronounced moisture differences.

Oct, I7, Section A: On this northern section we note that in the north, where the $\mathbf{P}_{\mathrm{P}}$ $\left(\mathbf{N}_{\mathrm{PP}}\right)$ cold front has been advancing steadily eastward, the slope and intensity of the front remain almost unchanged, and that the $\mathbf{N}_{P P}$ air mass remains quite homogeneous in the east-west direction. It will be noticed that the sounding from Boston on the following day has been used on this cross-section to fill in the gap left by the absence of a report from Chicago. This procedure is open to question. It is justified only when the translation of the whole air mass and frontal system is accurately known and is almost exactly parallel to the section, and when the air mass and frontal structures remain unchanged. These conditions are never completely fulfilled, and only rarely approximately so over a $24 \mathrm{hr}$. period. For soundings only a few hours apart the method is usually permissible. It has been used on a number of these cross-sections to that extent. But for a period of I 2 hrs. or longer, it must be used with caution, and only when the result is in good agreement with the rest of the section. In this case the agreement appears very good, except perhaps for a slight lifting of the topmost isotherm as a result of some subsidence aloft.

The three successive soundings at Boston give a detailed picture of the Tropical air mass structure just ahead of the cold front, a structure which has been mostly hypothetical on this section for the two preceding days. We find essentially a stratification of $\mathbf{T}_{\mathrm{S}}$ above $\mathbf{T}_{\mathrm{G}}$, with a doubtful narrow $\mathbf{N}_{\mathrm{TP}}$ transition zone between the two. The $\mathbf{T}_{\mathrm{G}}$ is definitely the colder air mass, and its rapid deepening ahead of the cold front is clearly shown by the upward spread of the high surface specific humidity, and the simultaneous deepening of the convective cumulo-nimbus clouds, culminating in moderate front passage showers. The same sequence was observed on Mt. Washington at the $2 \mathrm{~km}$ level, where unusually high temperatures and low relative humidity for more than $24 \mathrm{hrs}$. ( $\mathbf{T}_{\mathrm{s}}$ air mass) were followed by a slight fall in temperature and more than a doubling of the specific humidity ( $\mathbf{T}_{\mathrm{G}}$ air mass) which after a duration of about $8 \mathrm{hrs}$. was followed in turn by a very pronounced temperature fall ( $\mathbf{N}_{\mathrm{PP}}$ cold front).

In the far west there is noted a new $\mathbf{P}_{\mathrm{P}}$ cold front (an occluded front on the surface map) which retains a clearly marked trough of air of Tropical Pacific origin above the $2 \mathrm{~km}$ level.

Section B: On this north-south section it is seen that the $\mathbf{N}_{P P}$ cold front in the south has become almost stationary, and the cold air mass is much shallower than previously. In advance of this stationary cold front moist $\mathbf{T}_{\mathrm{G}}$ air has again displaced the $\mathbf{N}_{\mathrm{TP}}$ air mass appearing there on the previous day, but the warm dry $T_{S}$ current aloft has remained almost unchanged in the usual stratification pattern. It is notably warmer even than the $\mathbf{T}_{G}$ air mass. In the north the new $\mathbf{P}_{P}$ occluded front has advanced southward nearly to Omaha, with indications of a well marked trough of $\mathrm{N}_{\mathrm{TP}}$ aloft, probably coming well below the $2 \mathrm{~km}$ level.

An unlimited amount of detailed description might be written about the cross-sections presented in this paper, but the writing of it would not be justified. The attempt has been made to point out the more important and characteristic features of these sections, but infinite variation in the minor details of the frontal and air mass structures on individual sections makes further discussion of details rather pointless. 